\title{
Laser Scanning Measurements on Solar Cell Test Pattern NBS-22
}

W. F. Lankford, P. Kowalski, and H. A. Schafft

Electron Devices Division

Center for Electronics and

Electrical Engineering

National Engineering Laboratory

U.S. Department of Commerce

National Bureau of Standards

Washington, DC 20234

May 1981

Prepared for

$-Q C$ Solar Energy Research Institute

100 Golden, CO 80401

.456

Under contract EG-77-C-01-4042

$81-2260$

1901

Subcontract DX-1-1076-1 



\section{LASER SCANNING MEASUREMENTS ON SOLAR CELL TEST PATTERN NBS-22}

W. F. Lankford, P. Kowalski, and H. A. Schafft

Electron Devices Division

Center for Electronics and

Electrical Engineering National Engineering Laboratory

U.S. Department of Commerce National Bureau of Standards

Washington, DC 20234

May 1981

Prepared for

Solar Energy Research Institute

Golden, CO 80401

Under contract EG-77-C-01-4042

Subcontract DX-1-1076-1

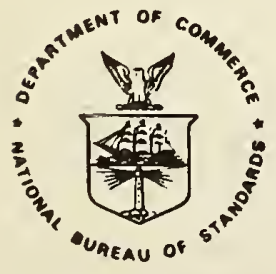

U.S. DEPARTMENT OF COMMERCE, Malcolm Baldrige, Secretary NATIONAL BUREAU OF STANDARDS, Ernest Ambler, Director 

Abstract . . . . . . . . . . . . . . . . . . . 1

1, Introduction . . . . . . . . . . . . . . . . . 1

2. Review of Previous Work . . . . . . . . . . . . . . . 4

2.1 The Solar Cell Test Pattern . . . . . . . . . . . . 4

2.2 Theoretical Calculations . . . . . . . . . . 6

3. Modifications of the NBS Laser Scanning System . . . . . . . . 8

4. Uniform Cell Scanning - Verification of the Calculated Predictions 21

4.1 Measurements and Analysis . . . . . . . . . . . . 21

4.2 Regions of Validity . . . . . . . . . . . . . 27

5. Detection of a Step Change in Sheet Resistance . . . . . . . . . 31

6. Detection of Noncontacted Metallization Regions . . . . . . . 37

7. Factors to Consider in the Redesign of the Solar Cell Test Pattern 38

7.1 Cell Configuration and Mounting . . . . . . . . . . 38

7.2 Step Change in Sheet Resistance . . . . . . . . . . . . 41

7.3 Illumination Uniformity and Intensity Calibration . . . . . 43

7.4 Temperature Sensor . . . . . . . . . . . . . 43

7.5 System Resolution .................. 44

8. New Directions . . . . . . . . . . . . . . . . . . 44 44

8.1 Contactless Measurement of Solar Cell Sheet Resistance . . . 44

8.2 On-Line Computer Use . . . . . . . . . . . . . 46

9. summary . . . . . . . . . . . . . . . . 46

Acknowledgments . . . . . . . . . . . . . . . . 47 47

References . . . . . . . . . . . . . . . . . 48

List of Figures

Page

1. Top view of the solar cell test pattern NBS-22 which includes four solar cells surrounded by sets of reference test structures . . .

2. Enlargement of the set of reference test structures on NBS-22 . . 3

3. Nature of metallization contact system . . . . . . . . . 5

4. Equivalent circuit of a solar cell with a laser spot at $x_{1}$ and a metallization spacing, s . . . . . . . . . . . . . . . 
List of Figures (continued)

Page

5. Calculated photoresponse of solar cell $\mathrm{C}$ to the laser spot as a function of spot position between metallization lines, separated by a distance $S$, for different ratios of attenuation length to separation distance . . . . . . . . . . . . . . . .

6. Three-dimensional presentation of normalized photoresponse as a function of laser spot position, $x_{1}$, normalized to attenuation length, $x_{0}$, near a break in metalijzation contact to the emitter surface for the case where the intermetallization spacing is twice the attenuation length ................

7. Block diagram of the $x-y$ recorder system for collecting solar cell line scans of photoresponse . . . . . . . . . . .

8. Photoresponse profiles from five line scans over a single 100metallization line for different objective-lens-to-solar-cell distances as indicated on each . . . . . . . . . . . . . .

9. Photoresponse profile from a single line scan over five adjacent metallization lines illustrating the effect of off-optical axis loss of resolution ......................

10. Photoresponse profile from a line scan under approximately one sun illumination showing the effect of illumination asymmetry . .

11. Illumination uniformity over a $2 \mathrm{~cm}$ by $2 \mathrm{~cm}$ area obtained from the photoresponse of a small area solar cell moved along parallel lines $2 \mathrm{~mm}$ apart in a test plane in the illumination field

12. Percent asymmetry in line scan versus percent nonuniformity in illumination level in the region of the scan ..........

13. Interference pattern in the photoresponse from a line scan due to multiple laser beam reflections between a solar cell and the objective lens ... . . . . . . . . . . . . . . .

14. Calculated photoresponse of a uniform cell to a laser spot for different attenuation lengths, $x_{0}$, expressed in terms of metallization spacing $S$, between metallization lines at $x=0$ and

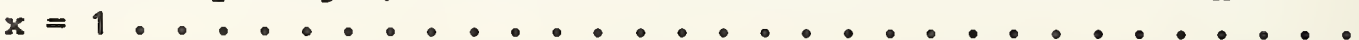

15. Measured photoresponse from a set of line scans between metallization lines of cell A for different levels of overall cell illunination

16. Curve fitting of eq (4) to photoresponse line scan data between metallization lines by minimizing chi squared 
17. Measured attenuation length versus short-circuit current for different levels of light bias for cell A, wafer $1 . . . . . . .$.

18. Measured attenuation length versus short-circuit current for different levels of light bias for cell A, wafer $2 ., . . . . .$.

19. Plot of measured attenuation lengths $x_{0}$ from table 2 for 0.97 suns illumination versus distance of the line scan from the solar cell bus bar, at $x=0$, indicating the region between 2 and $7^{\circ} \mathrm{mm}$ over which the predictions of eqs (3) and (4) are valid .....

20. Photoresponse profile from a line scan between metallization lines of cell $C$, wafer 9 , under a light bias of 2.1 suns ....

21. Digitized photoresponse data from a line scan between metallization lines of cell $\mathrm{c}$, wafer 1 . . . . . . . . . . . . .

22. Left portion of the photoresponse data shown in figure 21 where the line scan data are shown as $X^{\prime}$ 's and computed points from a best fit adjustment of attenuation length, $x_{0}$, are shown by dots

23. Central portion of the photoresponse data shown in figure 22 where the line scan data are shown as $X^{\prime \prime} s$ and computed points from $a$ best fit adjustment of attenuation length, $x_{0}$, are shown by dots . . . . . . . . . . . . . . . . . . . .

24. Complete fitted photoresponse curve with superimposed data from figure 22 where the central portion has been lowered for comparison between the three regions . . . . . . . . . . . . . .

25. Photoresponse line scans at 200- $\mu \mathrm{m}$ intervals of cell $\mathrm{B}$ in the vicinity of an $800-\mu \mathrm{m}$ break in metallization-to-emitter contact .

26. Photoresponse raster scan photographs in the vicinity of breaks in the metallization-to-emitter contact . . . . . . . . . . .

27. Revised arrangement for the solar cell test pattern showing the location of the diode, the thermocouple, TC, and the reference test structure, RTS . . . . . . . . . . . . . . . . . 
Page

1. Comparison of Notation in the Sawyer and Kessler and the Lehovec and Fedotowsky Analyses of Solar Cell Photoresponse to a Laser spot . . . . . . . . . . . . . . . . . . . . .

2. Attenuation Lengths Measured on Uniformly Diffused Solar Cell A of Wafer 1 . . . . . . . . . . . . . . . . . .

3. Attenuation Lengths Measured on Uniformly Diffused Solar Cell A of Wafer 2. . . . . . . . . . . . . . . . . . . .

4. Comparison of Sheet Resistances Measured by Optical and Electrical Methods . . . . . . . . . . . . . . . . . . 
Laser Scanning Measurements

on

Solar Cell Test Pattern NBS-22

by

\author{
W. F. Lankfor $\mathrm{d}^{*}$ * \\ P. Kowalski, and H. A. Schafft \\ Electron Devices Division \\ National Bureau of Standards \\ Washington, DC 20234
}

The NBS laser scanner has been used to make measurements on the solar cell test pattern NBS-22 to verify the theoretical calculations of sawyer, Lehovec, and Fedotowsky. The photovoltaic response from cells with controlled sheet resistance step changes and breaks in the metallization contact to the cell was measured and compared to the theoretical predictions. Laser scanner limits of resolution are identified and proposed improvements are discussed. Preliminary measurements indicate that it is possible to measure the sheet resistance of the emitter layer of solar cells with an accuracy of several percent using the laser scanner.

Key Words: Laser scanner; model calculations; photovoltaic cells; sheet resistance; solar cells; solar cell defects; test structures.

\title{
1. Introduction
}

The application of the laser scanner to the study of solar cells injtiated by Sawyer [1-4] at the National Bureau of Standards (NBS) has continued in a program to quantify its measurement potential and to evaluate its use in the detection of specific cell defects. The principal thrust of this report is to describe experimental verification of the theoretical photoresponse curves predicted by Lehovec and Fedotowsky [5] of the University of Southern California. In addition, the resolution limits of the National Bureau of Standards scanner in the study of solar cell imperfections are defined and inherent limits in the application of laser scanner techniques to the detection of defects in solar cells are identified as they relate to laser scanners in general.

The first step in the verification of the theoretical results is the direct comparison of the measured photoresponse from the laser spot scanned along a single line across solar cell A of the solar cell test pattern, NBS-22, shown in figure 1 with the curves predicted by Lehovec and Fedotowsky for a uniform cell. Two approaches were taken. A point-by-point comparison between data and prediction verified the correctness of the photoresponse equation within our experimental accuracy. Then a quantitative comparison based on sheet resistance measurements from the reference test structures of NBS-22, shown enlarged in figure 2, confirmed the correctness of the equation. The impor-

* Professor of Physics, George Mason University, Fairfax, VA 22020. 


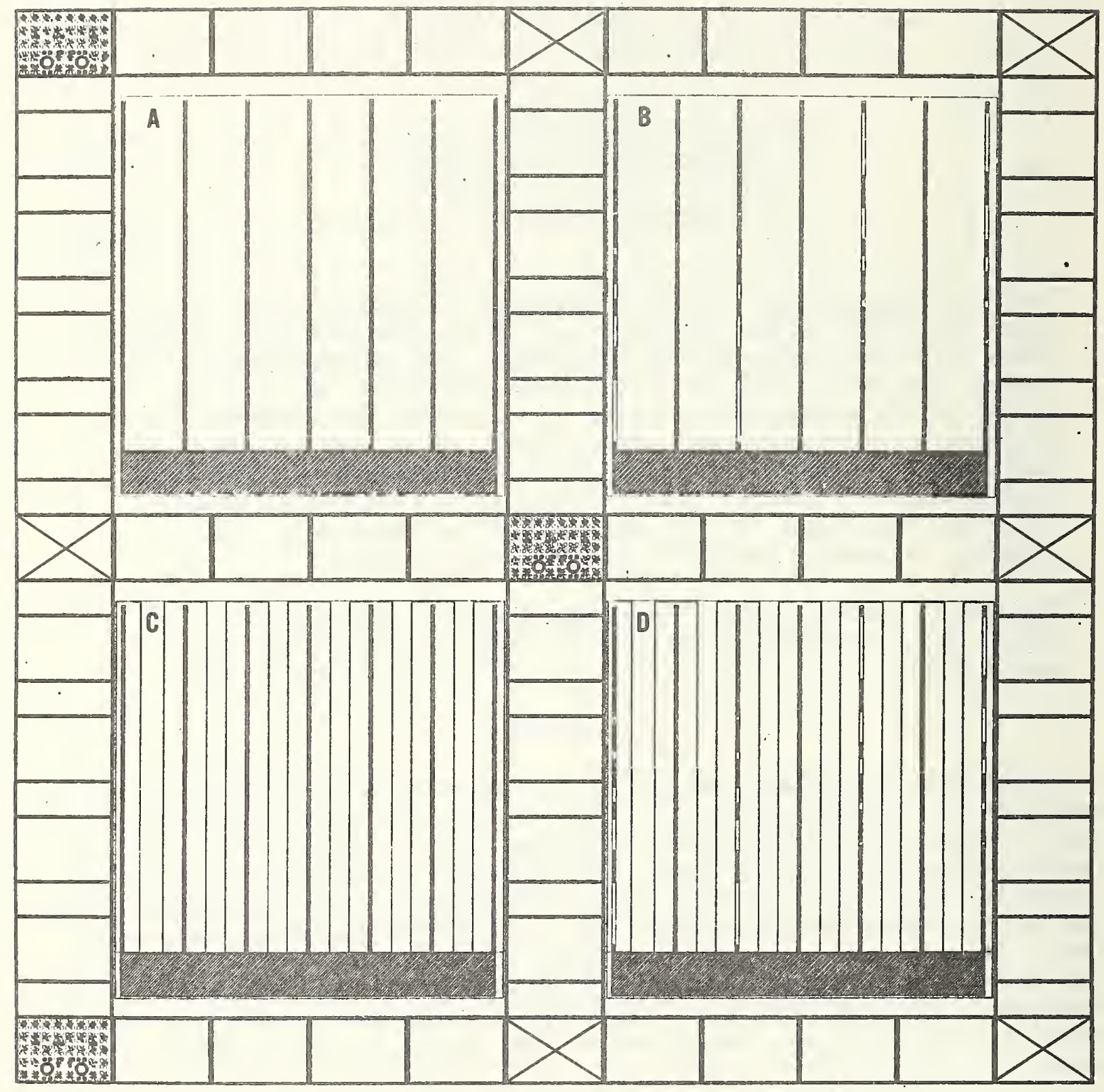

Figure 1. Top view of the solar cell test pattern NBS-22 which includes four solar cells (A, B, C, and D) surrounded by sets of reference test structures. These sets are present in each of the larger rectangles not containing a diagram of the set or an "X" (i.e., 16 sets around each cell). The gaps in the metallization contact are indicated by the open rectangles on cells $B$ and $D$. 


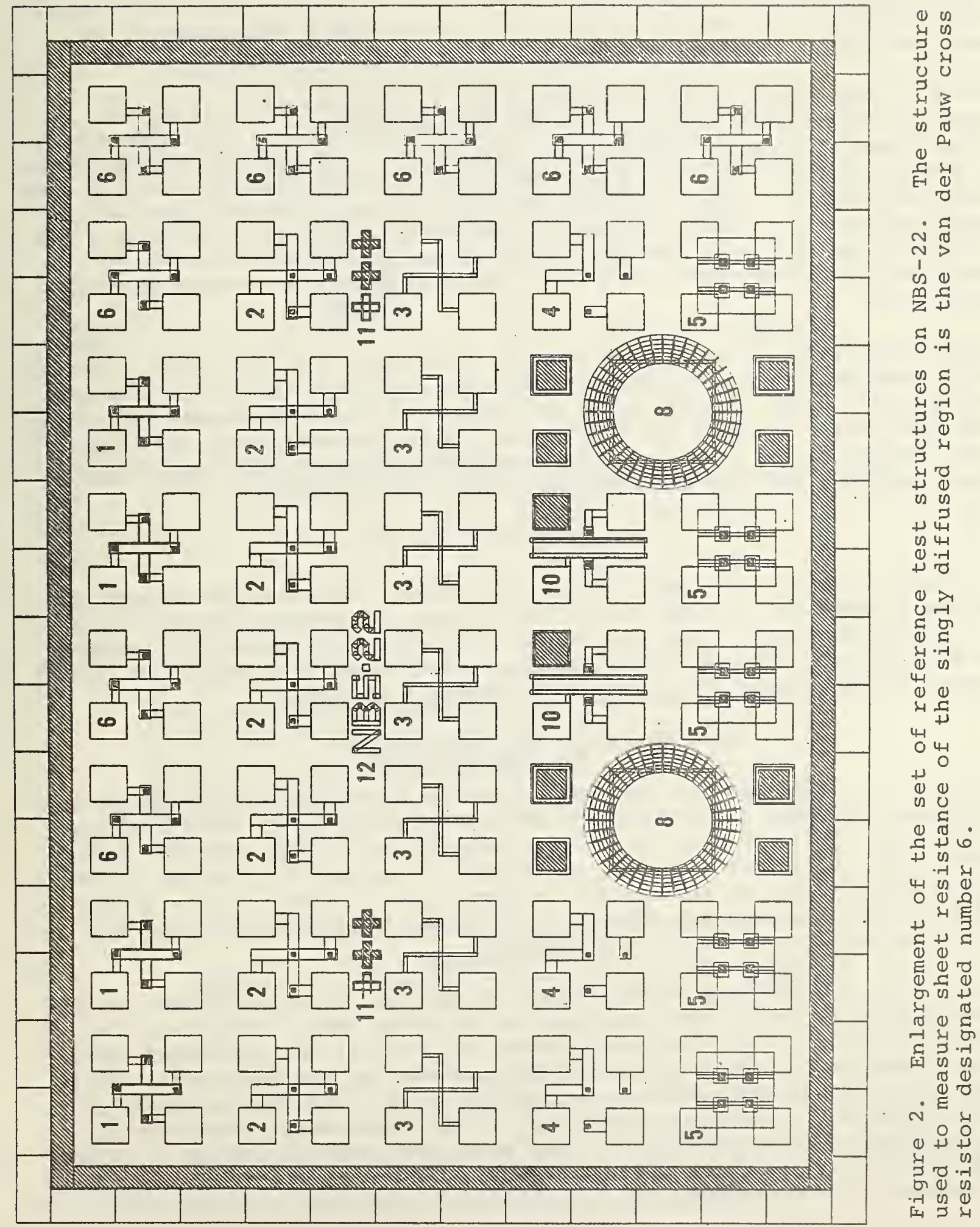


tance of this result is that the dependence of the photoresponse on the position of the light spot relative to a metallization line may be predicted for various levels of full cell illumination. This dependence may then be separated from photoresponse variations due to cell defects independently of where the defect happens to be located.

With the characteristic photoresponse curve established for a line scan across an illuminated perfect cell, the scanner was applied to the detection of two types of controlled defects or variations. The first is a step change in sheet resistance due to a second diffusion of phosphorus into the top surface. The second controlled defect studied is a gap in contact between the metallization and the top surface as illustrated in figure 3 for cells $B$ and $D$ of the solar cell test pattern. Scans of the cell in the vicinity of breaks of 200 to $1600 \mathrm{jm}$ in length were made to determine the minimum length detectable.

Several modifications which were made in the scanner system to permit quantitative measurements are described. Experience with the solar cell test pattern has led to the identification of a number of proposed changes and extensions that would increase its usefulness. These are described, and further modifications in the scanner system itself are discussed which would make it a more powerful tool for the analysis of solar cell defects.

\section{Review of Previous Work}

In order to provide the reader with a more nearly self-contained report, the results of previous work which were used in the measurements reported here are briefly described. They are 1) the solar cell test pattern [4] on which the measurements are made and 2) the theoretical results of Sawyer [3] and of Lehovec and Fedotowsky [5] on which the analysis is based.

\subsection{The Solar Cell Test Pattern}

The solar cell test pattern (designated NBS-22) developed for this study contains four $n-p$ solar cells, three of which have intentional, controlled imperfections. Cell A has no intentional defects, cell B has different length gaps in the metallization contact to the cell's top surface (but not in the metallization itself as illustrated in figs. 1 and 3 ), cell C has a doubly diffused region beneath and adjacent to each metallization grid line, and cell $D$ has the defects of $B$ and $C$ combined.

Surrounding each cell are 16 repetitions of the set of reference test structures fabricated by the same processes as the solar cells. These are used to obtain independent electrical measurements of critical cell parameters such as sheet and metallization contact resistance made on the same wafer. These measurements are used to verify that the solar cells have been properly produced and provide a comparison with the optical measurements made with the laser scanner. The entire NBS-22 solar cell test pattern is shown in figure 1 , and the set of reference test structures is shown in figure 2. A detailed description of the reference test structures is contained in reference 4. 

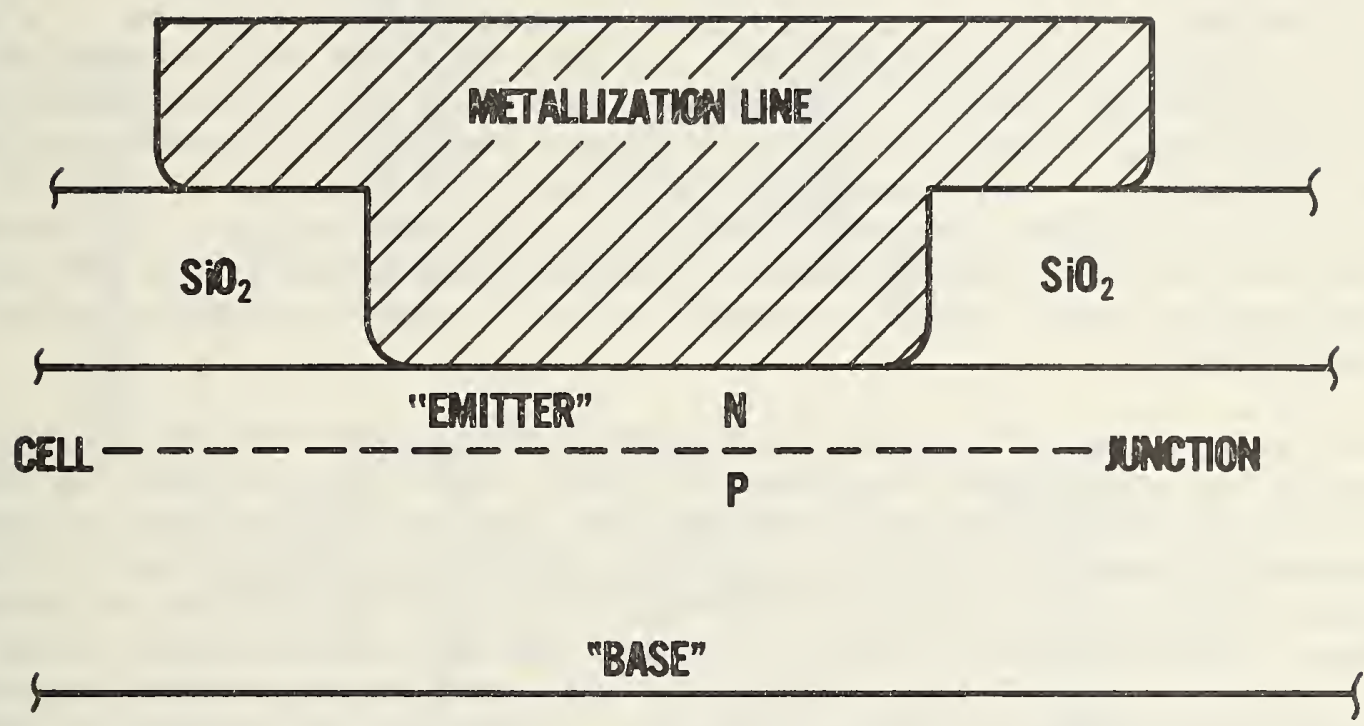

a. Metallization in proper contact with solar cell emitter, not to scale.

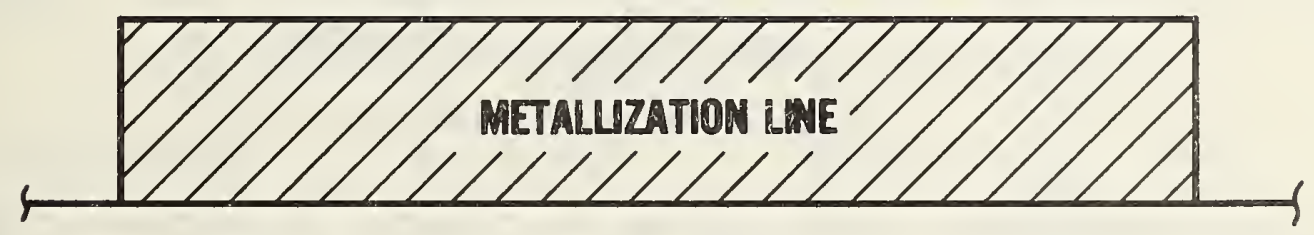

$\mathrm{SiO}_{2}$
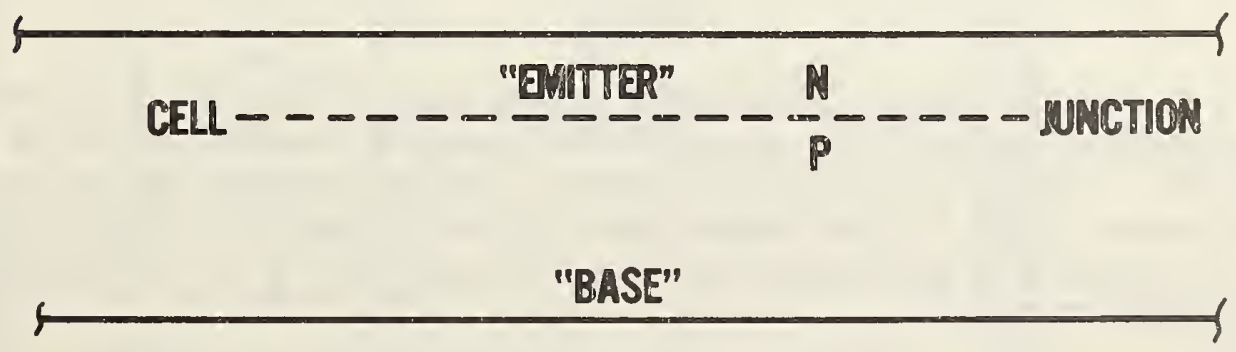

b. Region of the metallization with a break in metal-to-emitter contact as fabricated in cells $B$ and $D$ of the solar cell test pattern, not to scale.

Figure 3. Nature of metallization contact system. 


\subsection{Theoretical Calculations}

An analysis of the photoresponse of a solar cell to a line of light parallel to a metallization line while the cell is uniformly forward biased by background illumination was made by Sawyer and Kessler [3] and extended to a spot of light by Lehovec and Fedotowsky [5]. In each case the cell is modeled as a network of discrete resistors and diodes comprising the various series and shunting impedances to current into an external load for an illuminated cell as shown in figure 4. The primary source of series resistance to lateral current flow is the sheet resistance of the top diffused region. Other contributions such as the surface-to-metallization contact resistance and the metallization resistance itself are small in well-constructed solar cells and may be neglected.

The resistance of the cell to vertical current across the cell in figure 4 is comprised of the resistance associated with the diode junction and the bulk resistance of the $n$-type material between the junction and the back contact. The photocurrent generated by the laser spot while the cell is forward biased by uniform illumination encounters the bulk resistance as part of its series resistance, although this resistance is small and may be neglected in the analysis. However, the forward conducting elemental diodes surrounding the light spot act as shunts to the photocurrent, reducing the current collected at the metallization grid. This may be expressed as the forward diode conductance which is dependent on the forward biasing of the cell, and thus on the level of overall illumination on the cell.

The expression derived by sawyer [3] for a scanning light line of length w expresses the small-signal output voltage, $v_{\text {out }}$ of the cell across an external load, $z_{\ell}$ in terms of the laser-generated current $i_{p}$ :

$$
v_{\text {out }}=i_{p} z_{\ell}\left\{\frac{\sinh [\beta(\ell-x)]+\sinh (\beta X)}{\sinh (\beta \ell)+\frac{2 w \beta Z}{\Omega_{s}}[\cosh (\beta \ell)-1]}\right\} \text {, }
$$

where $l$ is the metallization spacing, $x$ is the location of the line of light from a metallization line, $w$ is the length of the line of light, and $\Omega_{s}$ is the sheet resistance. The important parameter $\beta$ is defined as

$$
\beta=\sqrt{\Omega_{\mathbf{s}} \sigma_{p}},
$$

where $\sigma_{p}$ is the small-signal diode shunt conductance per unit area evaluated at the dc operating point. The coefficient $\beta$ may be considered to be a curvature parameter of the photoresponse curve measured between metallization lines. The second term in the denominator of eq (1) may be neglected compared to the first if $\mathrm{w}$ is reduced to a small spot and $z_{\ell} \ll \Omega_{s}$ as is the case for our measurements.

Lehovec and Fedotowsky [5] solved the wave equation for a lossy medium:

$$
\nabla^{2} \mathrm{v}=\mathrm{v} / \mathrm{x}_{0}^{2},
$$

for the photogenerated potential $\mathrm{V}$ due to the laser spot. The attenuation length, $x_{0}$ is defined as the distance from the light spot to a metalliza- 


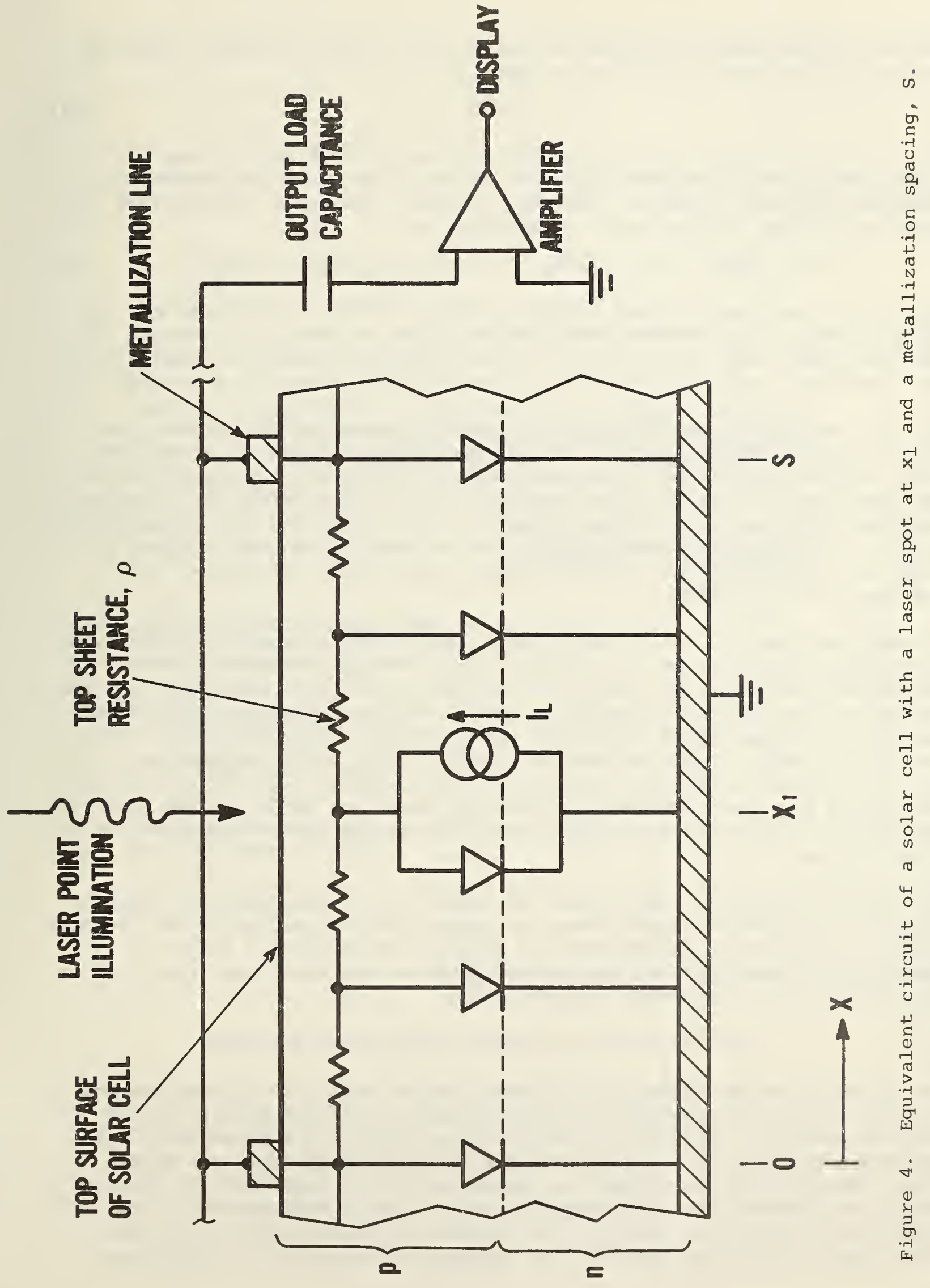


tion line, such that the current is reduced by $1 / e$ due to losses across the photovoltaic junction. It is given by:

$$
x_{0}=\sqrt{2 / p} \text {, }
$$

where $\mathrm{z}^{-1}$ is the diode conductance per unit area, and $\rho$ is the sheet resistance of the illuminated diffused region. The resulting expression, assuming negligible external load, for the total current I collected by the metallization due to the laser illumination is

$$
I=I_{I}\left\{\left\{\sinh \left[\left(S-x_{q}\right) / x_{0}\right]+\sinh \left[x_{1} / x_{0}\right]\right\} / \sinh \left(s / x_{0}\right)\right\} \text {, }
$$

where $I_{I}$ is the laser-induced current at the location of the laser spot $x_{1}$, and $S$ is the spacing between metallization lines as shown in figure 4. It should be noted that the only term in this expression which is dependent on the electrical parameters of the cell itself is the attenuation length, $x_{0}$.

With the identification of $\beta$ in eq (1) as the inverse of the attenuation length, the two expressions (1) and (5) become equivalent. It should be noted that the dependence of the photocurrent collected on the position of the laser spot is solely in the numerator of each expression. It is this dependence that is used for the analysis of the fault-free cell in section 4. A list of corresponding terms used by the two sets of authors is given in table 1. In the remainder of this report, the notation of Lehovec and Fedotowsky will be used.

The photoresponse of a cell containing a step change in sheet resistance, as introduced in cells $C$ and $D$ of figure 1, was calculated numerically by Lehovec and Fedotowsky [5] assuming that this is the only parameter that has changed in this portion of the solar cell. The lower doping concentration results in a higher sheet resistance which produces slightly greater curvature in the center region as seen in figure 5 for a sheet resistances of 45 $\Omega / \square$ in the center region and $31 \Omega / \square$ in the side regions next to the metallization. As will be discussed in section 5, there are other changes that can contribute to significantly greater photoresponse in the center (less heavily doped) region.

The solution of eq (3) for the case of breaks in the metallization contact cannot be obtained in closed form. An example of the results of the required numerical calculation is presented in figure 6 which shows a three dimensional presentation of the photoresponse in the area where the break in the metallization-to-emitter contact begins.

\section{Modifications of the NBS Laser Scanning System}

Two capabilities were added to the laser scanner during this reporting period to aid in making the measurements for comparison with the results of the previous section. The first allows the output from the scanned cell to be obtained accurately as a permanent trace on an $x-y$ recorder. To achieve this, a mechanical beam chopper was installed in the laser beam to produce a modulation frequency of approximately $250 \mathrm{~Hz}$. The photoresponse of the cell to the pulsed light was capacitively coupled to the low-noise audio transformer used in previous studies [2]. However, in place of the high gain 
Table 1. Comparison of Notation in the Sawyer and Kessler [3] and the Lehovec and Fedotowsky [5] Analyses of Solar Cell Photoresponse to a Laser Spot.

\begin{tabular}{lcc}
\hline Parameter & $\begin{array}{c}\text { Sawyer and } \\
\text { Kessler }\end{array}$ & $\begin{array}{c}\text { Lehovec and } \\
\text { Fedotowsky }\end{array}$ \\
\hline metallization spacing $[\mathrm{mm}]$ & $\ell$ & $\mathrm{s}$ \\
laser spot position [mm] & $\mathrm{x}$ & $\mathrm{x}_{1}$ \\
attenuation length [mm] & $\frac{1}{\beta}$ & $\mathrm{x}_{0}$ \\
sheet resistance $[\Omega / 0]$ & $\Omega_{\mathrm{s}}$ & $\rho$ \\
diode shunt conductance & $\sigma_{\mathrm{p}}$ & $\frac{1}{\mathrm{z}}$ \\
per unit area $\left[\mathrm{S} / \mathrm{m}^{2}\right]$ & ${ }^{2}$ & \\
\hline
\end{tabular}




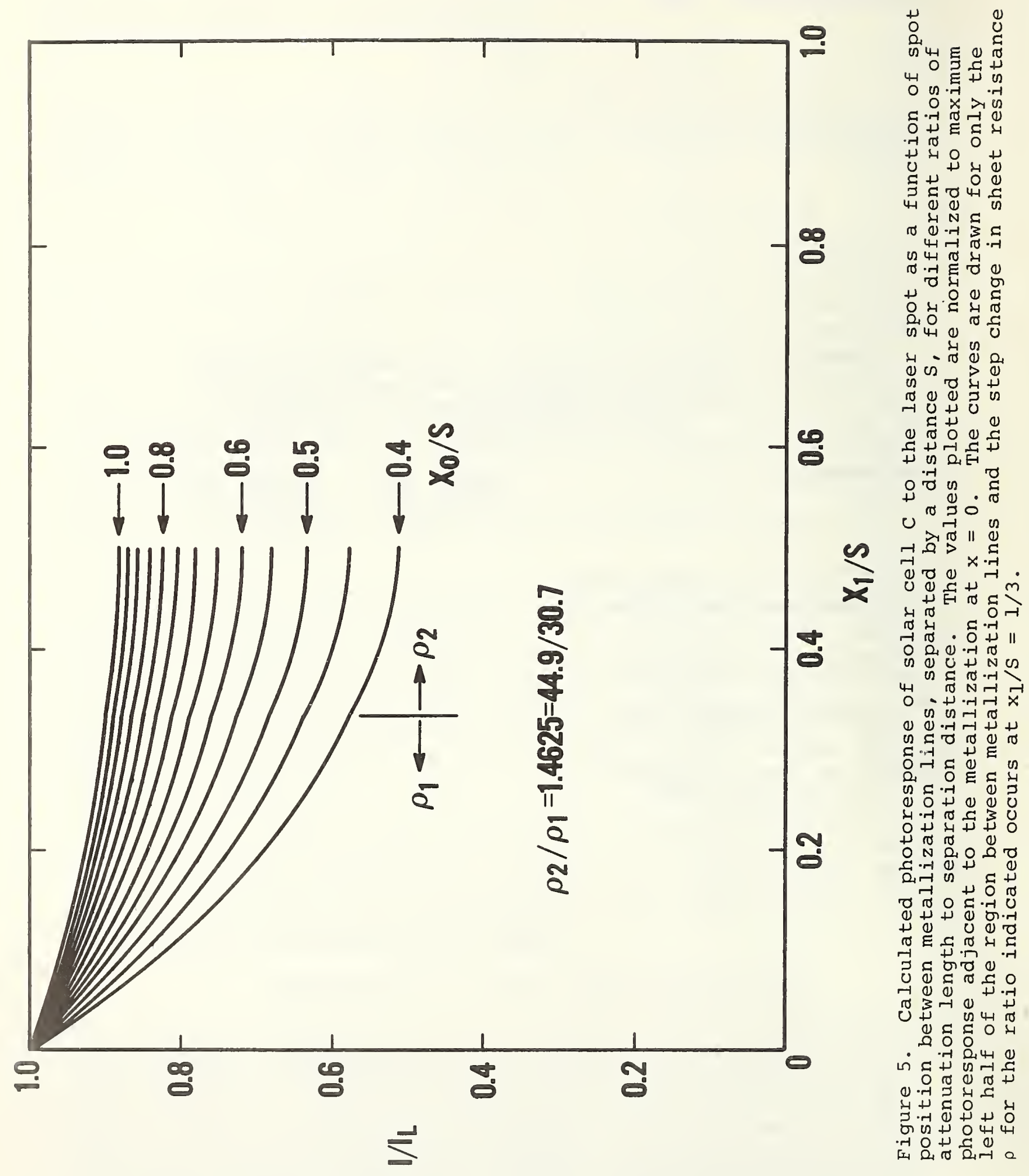




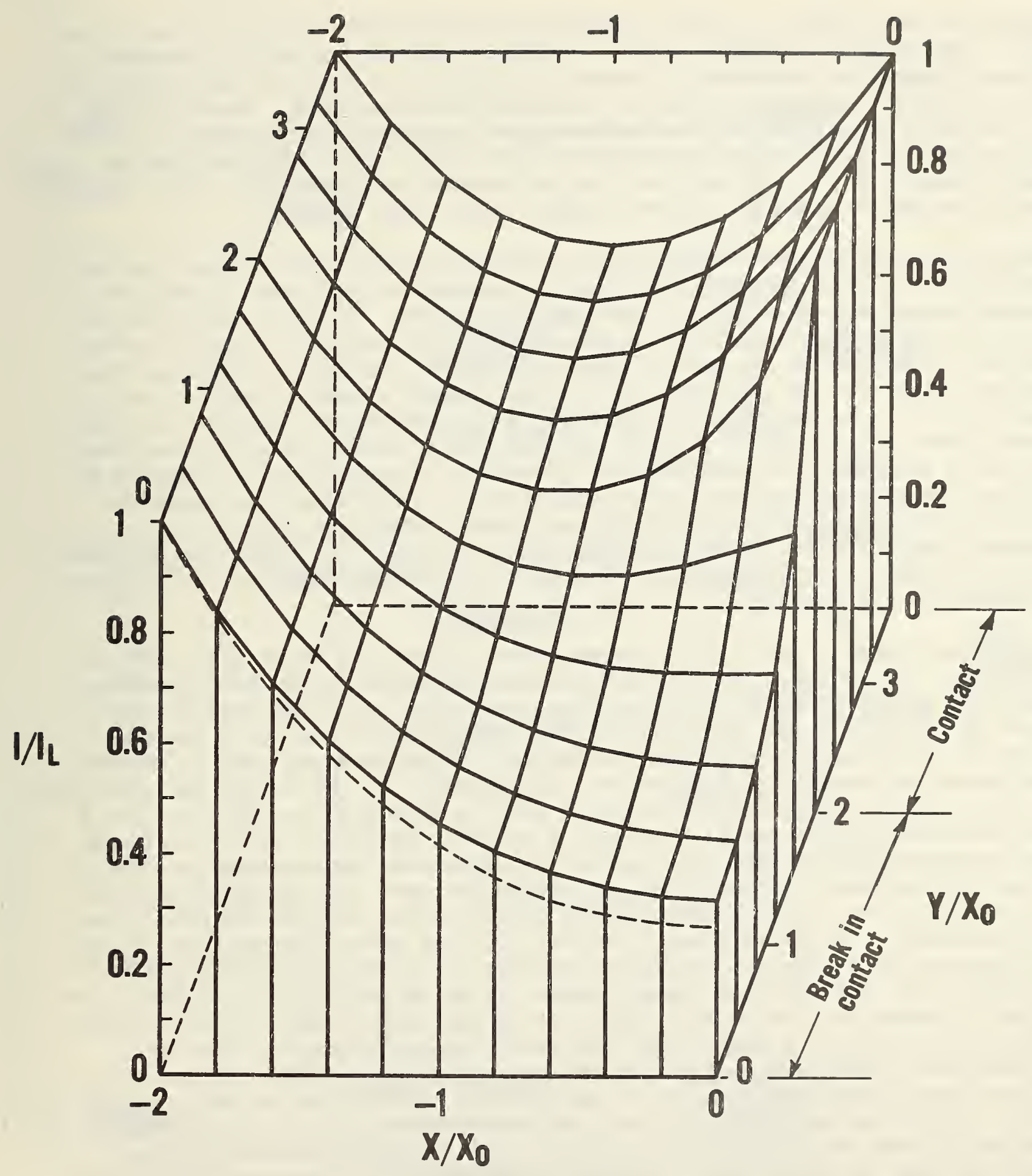

Figure 6. Three-dimensional presentation of nor!llalized photoresponse (vertical axis) as a function of laser spot position, $x_{1}$, normalized to attenuation length, $x_{0}$, near a break in metallization contact to the emitter surEace for the case where the internetallization spacing is twice the attenuation length. The metallization is parallel to the $y$-axis at $x / x_{0}=0$ and -2 . 
amplifier used before, a lock-in amplifier tuned to the chopper frequency was used. The lock-in amplifier output was then displayed on the $x-y$ recorder. A block diagram of the setup is shown in figure 7. A detailed description of the transformer coupling system is contained in reference 2 . When the cell is uniformly illuminated with constant light, the blocking capacitor provides for dc open-circuit and ac short-circuit operation. The resulting low RC time constant of the cell and its load allows the cell to reach steady output during the approximately $4 \mathrm{~ms}$ the chopped laser light is on.

The previous technique of sweeping the unmodulated laser spot across the cell sufficiently fast to produce a fluctuating signal at cell defects requires a greater sweep rate than the $x-y$ recorder can follow. In order for an $x-y$ recorder or other data acquisition system such as an analog to digital converter for a computer to be used with the scanner in the flying spot mode, the response time must be less than the time of transit across a defect. For a $1-\mu \mathrm{m}$ crack at a relatively slow scan rate of $5 \mathrm{~m} / \mathrm{s}$ (permitting about one full raster scan of a $1 \mathrm{~cm}$ by $1 \mathrm{~cm}$ cell per second), a response time of less than $0.2 \mathrm{\mu s}$ is required. In the modified system the ac modulation is supplied by the laser beam chopper. In this configuration, with the lock-in amplifier measuring the amplitude of the modulated signal, the laser spot can be scanned across the cell slowly enough for the recorder to follow the photoresponse signal. A more detailed permanent record is thus obtained in place of the previous CRT display.

The second addition was a motor-driven stage to move the solar cell under a stationary laser beam. When the detailed $x-y$ recorder traces from a moving spot were examined, it became clear that variations due to optical aberrations in both the focus and the intensity of the laser beam as it traversed slightly different paths through the optical system produced greater effects than those we hoped to study from the cell itself. The effect of variation in focal length can be seen in figure 8 where a line scan is taken over a $100-\mu \mathrm{m}$ wide metallization line of cell A of the solar cell test pattern for five different objective-lens-to-solar $\rightarrow$ cell distances as indicated on each. At the second line from the right, the effective spot size is about $40 \mu \mathrm{m}$ as measured from the sloped portion of the photoresponse line at the metallization boundary. At the leftmost line, the spot has grown to more than $100 \mu \mathrm{m}$ in diameter for a change in objective lens to sample distance of only $3 \mathrm{~mm}$. A single line scan over five metallization lines of solar cell A of NBS-22 is shown in figure 9. The varying spot size is due to increased optical aberrations for the off-axis laser beam that result in poorer focus. The onoptical axis laser beam strikes the cell at the point indicated by the dot midway between the second and third metallization line from the left of the scan. The photoresponse minima over the adjacent metallization lines are beginning to show the distortions associated with off-axis scanning in the sloped bottoms of the minima. The scan across the far right-hand metallization line shows a trace that is comparable in shape and relative depth of minimum to the $45-\mathrm{mm}$ focal length scan seen in figure 8 and thus is equivalent to being about $2 \mathrm{~nm}$ out of focus. Similar results were seen at smaller working distances and higher resolution.

These effects are eliminated by adjusting the scanning mirrors to keep the laser beam fixed along the optical axis and moving the cell. The $x$-axis drive for the $x-y$ recorder is controlled by the motor drive so that the re- 


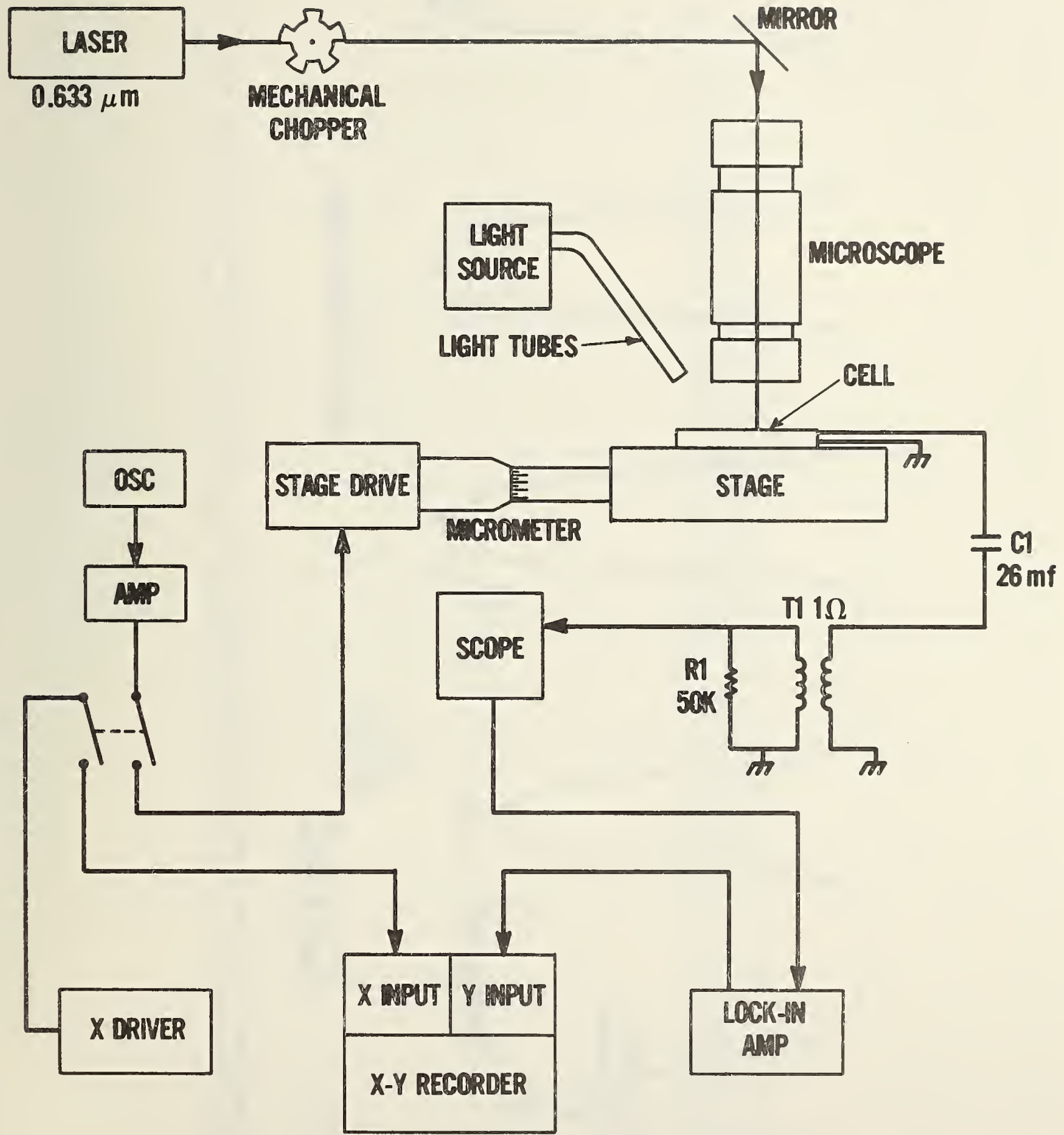

Figure 7. Block diagram of the $x-y$ recorder system for collecting solar cell line scans of photoresponse. The cell is moved by the stage and the laser spot is stationary. 


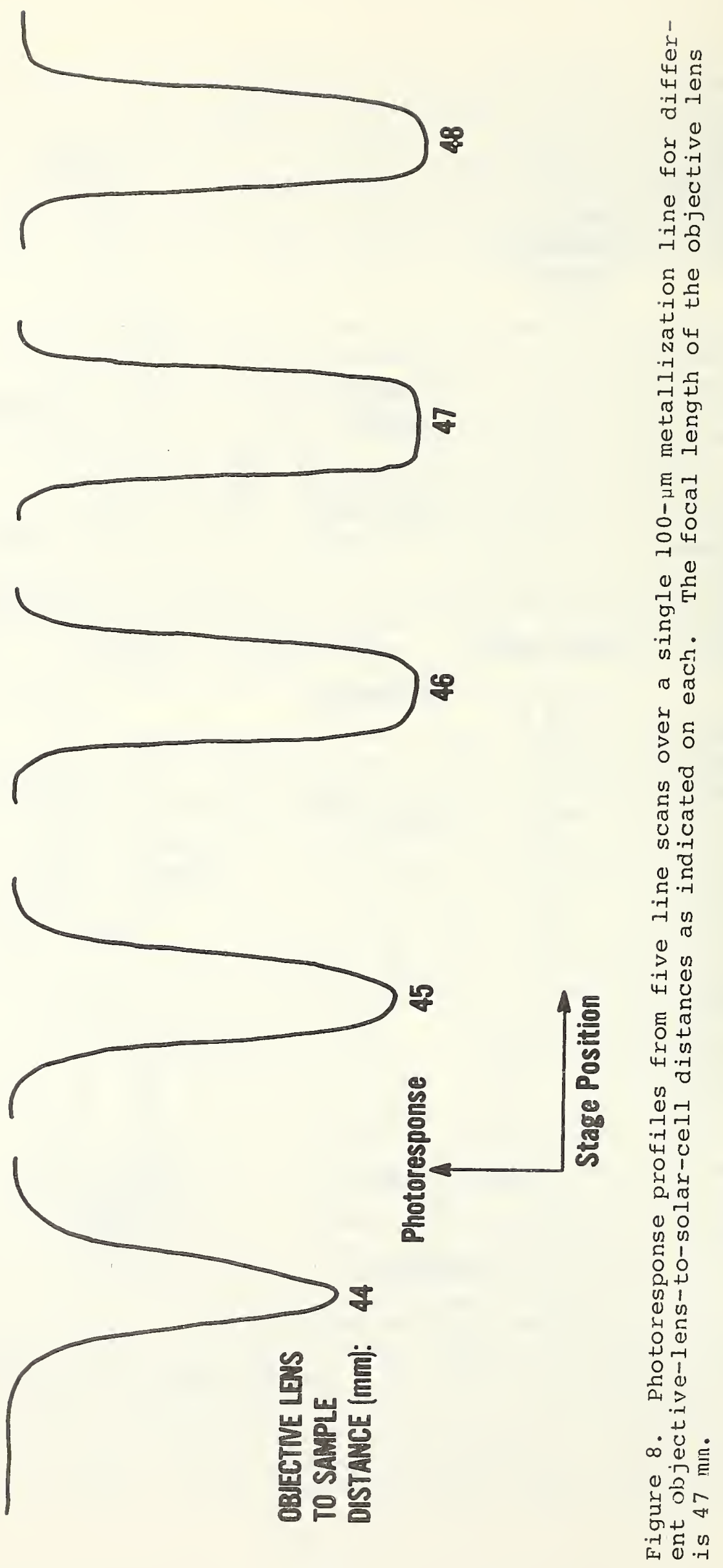




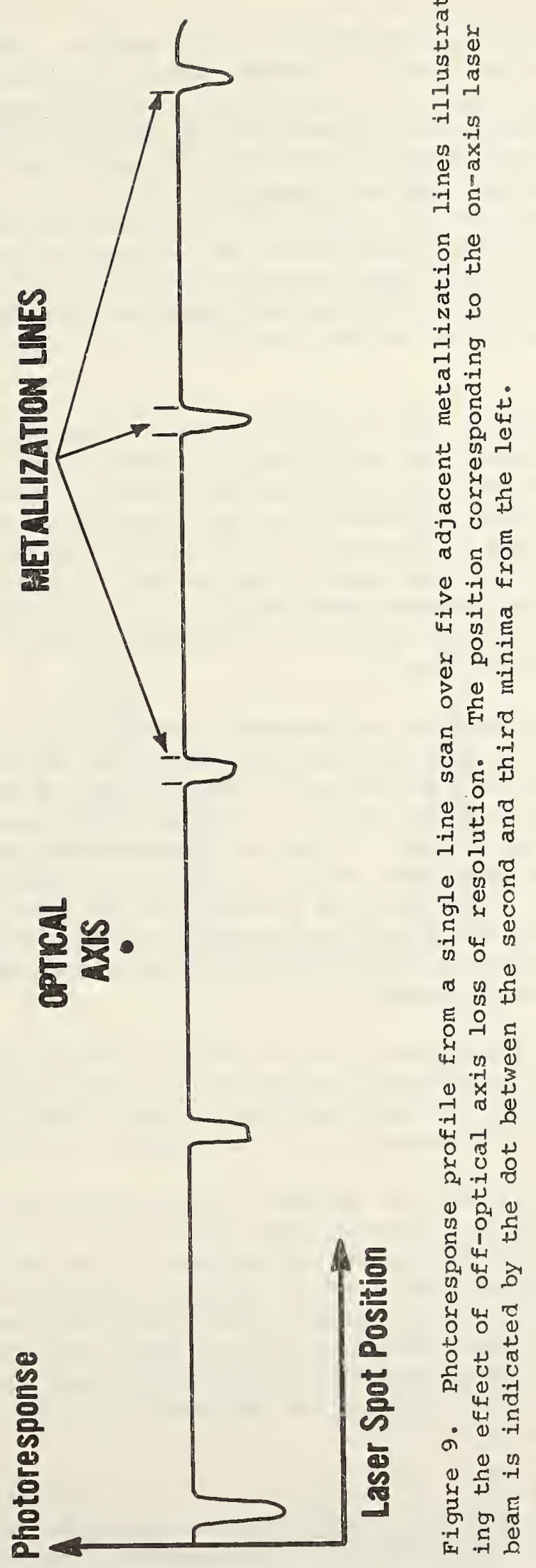


corder pen drive is synchronized with the cell motion. Any changes in the photoresponse from the cell as it is moved under the laser spot can then be unambiguously related to variation in the cell rather than in the light probe. This also facilitates alignment of the optical system for optimum focus and eliminates variations in intensity as well. As may be inferred from figure 8 , vertical variations present in commercial stages of the order of $\pm 0.02 \mathrm{~mm}$ in the position of the cell as the stage is moved horizontally are inconsequential to our measurements. An alternative way of dealing with the problem of variable laser spot intensity has been developed by Wagner et al. [6] based on an optical system developed by Distefano [7]. This system employs collimators which necessitate the use of a substantially higher power laser.

An example of the advantage of the modified NBS system is that a slight nonuniformity in the dc light bias can clearly be seen as an asymmetry in the photoresponse curve between two metallization lines as discussed below. A nonuniformity of less than 1 percent over an intermetallization distance of $1.5 \mathrm{~mm}$ is readily seen as a difference in photoresponse at the two ends of the line scan. Figure 10 shows such a scan under a light bias of approximately one sun where the maximum photoresponse with the laser spot adjacent to the metallization on either side is 2.2 percent higher on the right due to the nonuniformity of light bias.

A study was made of the general relationship between the nonuniformity of illuminating light bias and the resultant asymmetry in the line scan between two metallization lines on a solar cell. The uniformity of illuminating light was measured with a solar cell, with dimensions $1 \mathrm{~mm}$ by $4 \mathrm{~mm}$, as it was moved over the illuminated area. A typical three-dimensional presentation of a map of a $2 \mathrm{~cm}$ by $2 \mathrm{~cm}$ area made on an $x-y$ recorder is shown in figure 11, where the $x$ - and $y$-axes represent the position of the test cell and the z-axis displacement is proportional to the photocurrent from the test cell. In this example, reasonably good uniformity is seen over most of the upper left quarter of the area measured.

To make a quantitative measurement of the average nonuniformity, the test cell was moved over a distance of $4 \mathrm{~mm}$ in the illumination field. Then cell A of NBS-22 was placed at the same position in the illuminated field and a line scan was made over a distance of $1.5 \mathrm{~mm}$ between two metallization lines.

The relationship obtained between asymmetry and nonuniformity, measured in this way is consistent with a linear dependence as shown in figure 12. The effect is due to the increased diode conductance in the cell with light bias. The error bars represent estimates of uncertainty primarily associated with the placement of the cell. The average light bias level was approximately 0.4 suns. A small test cell incorporated into solar cell test pattern would aid in making these two measurements at exactly the same place in the field. It would also be useful in verifying the uniformity of the illuminating field as will be discussed in section 7.3 .

Another problem to be avoided in the line scan of a cell directly under the microscope objective is multiple reflections between the cell and the bottom of the objective lens. The effect is illustrated in figure 13 where an interference pattern is seen in the central portion of the scan. The undesir- 


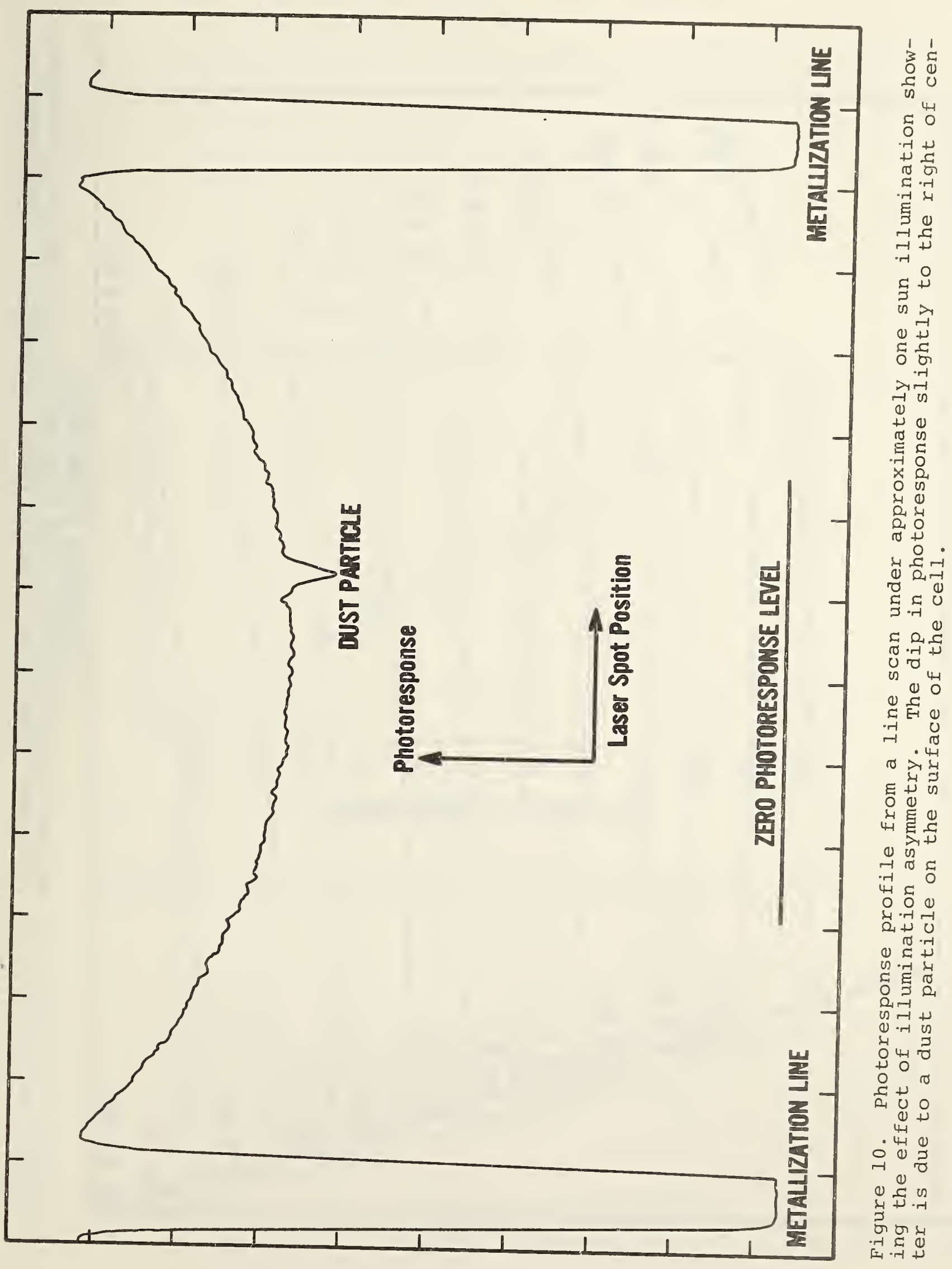




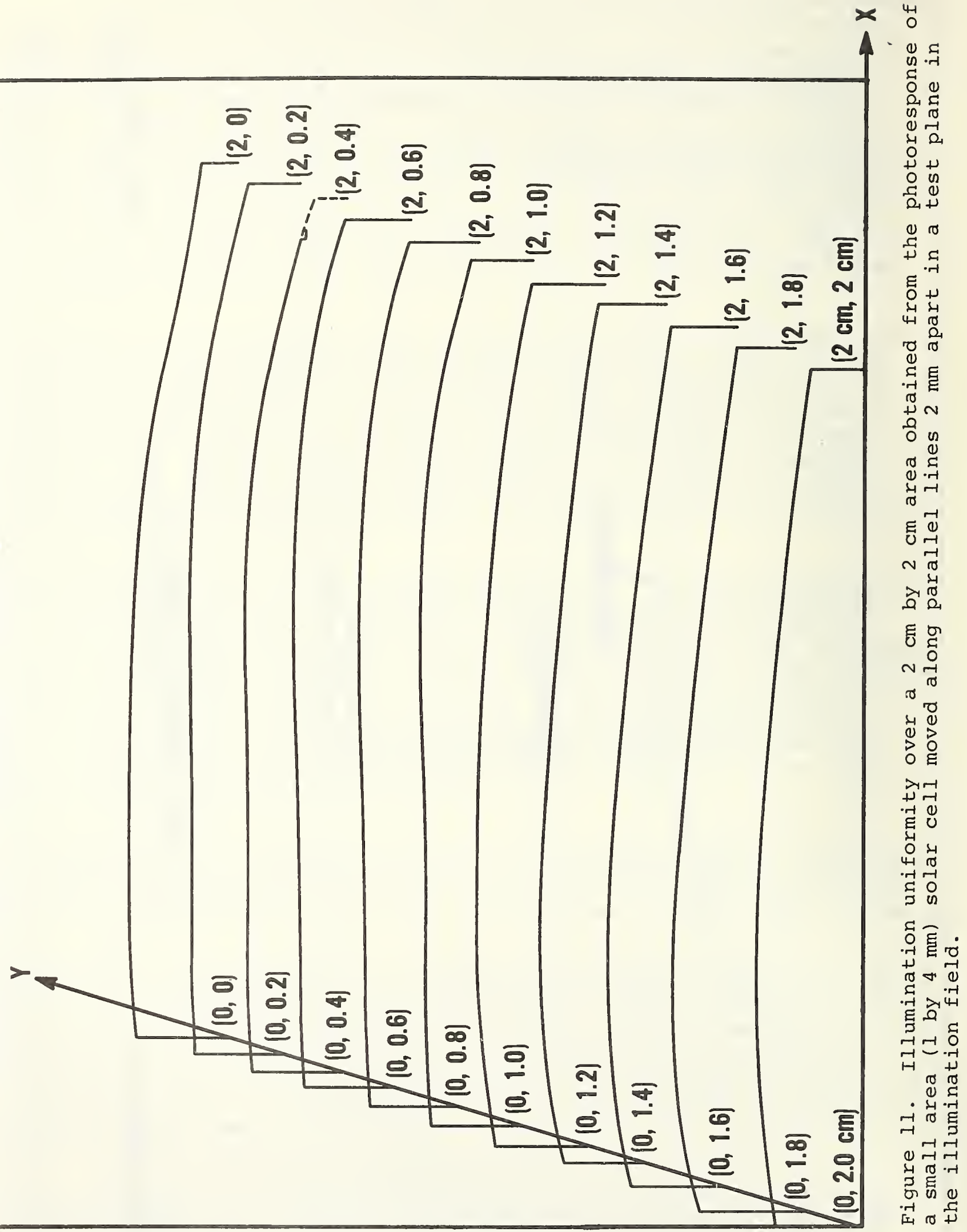




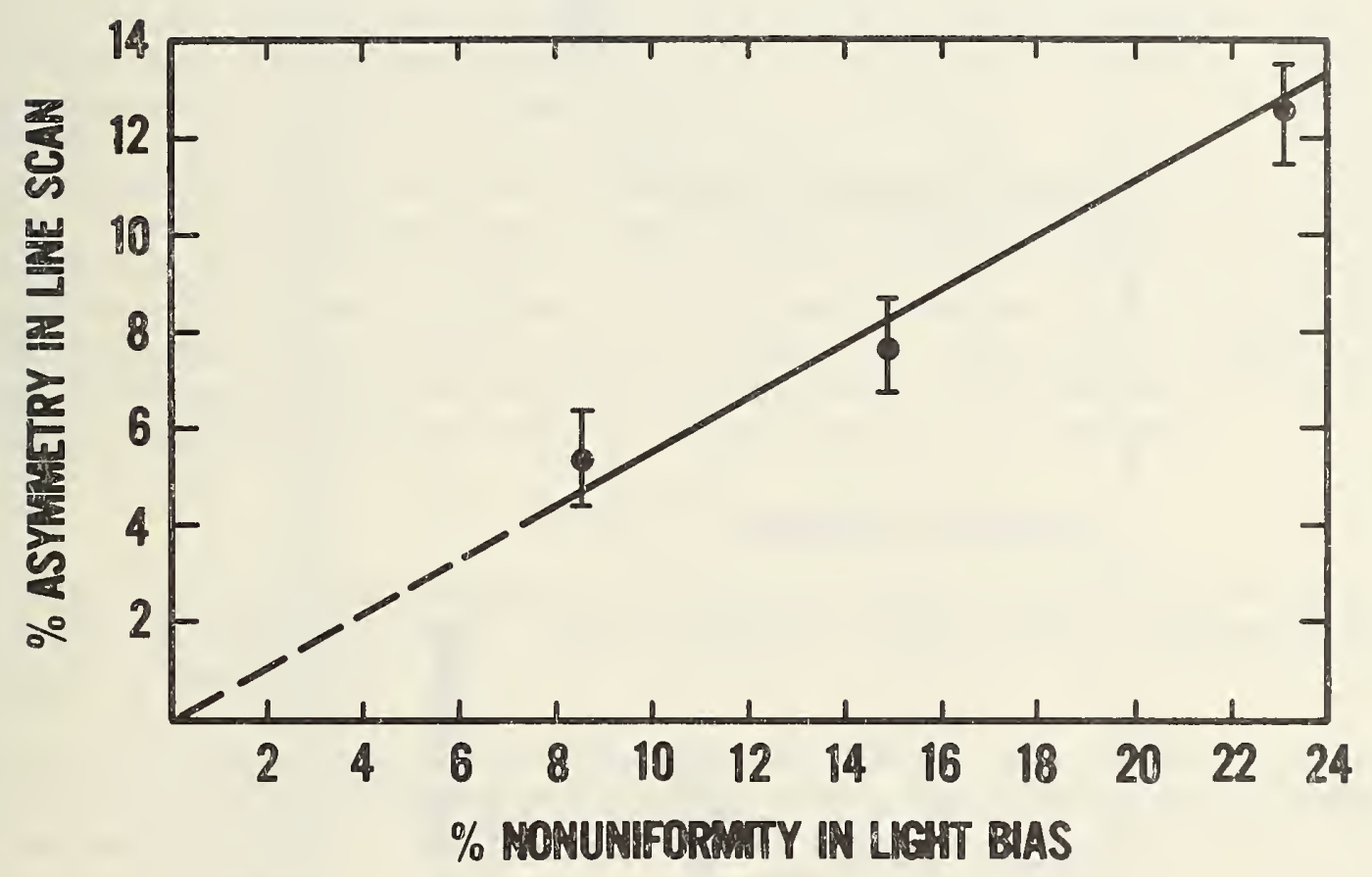

Figure 12. Percent asymmetry in line scan versus percent nonuniformity in illumination level in the region of the scan. 


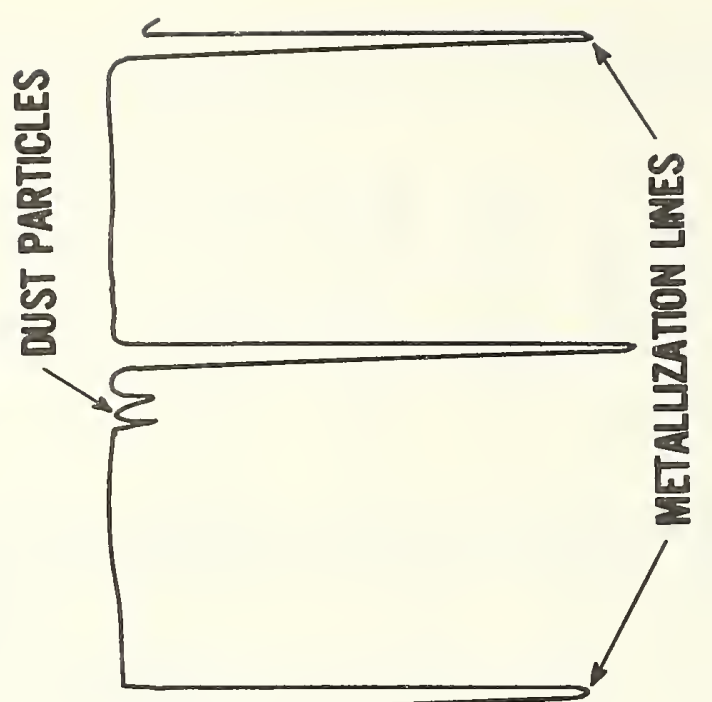

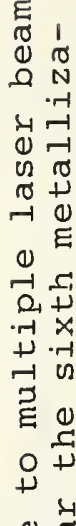

Ð

(1) .

U

(1).

43

$-1$

ه

등

㟧

(1)

¿

ค

叶

\& 0

00

$+1$

동
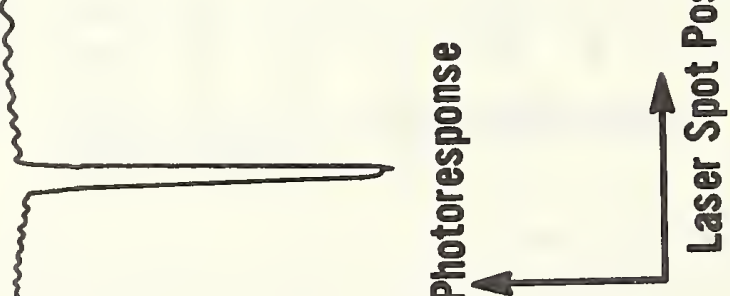

(1)

प)

+ -

व

हैन

넌

$+1$

त.

(1)

0 un

(1)

00

幽这

4⿺辶寸

先䓵

网,

n $\cdot-1$

लं 0

त. त्र ह

(1) Uन

(4)

वुस द्व

वाय 40

[ᄃㄴㄷㅏ 
able reflections may be eliminated by tilting the cell about an axis lying in the direction of the line scan through an angle large enough such that the secondary reflected beam does not fall back on the cell. The decrease in photoresponse as the laser spot crosses a metallization line is also seen to vary systematically as the laser beam gets further off the optical axis. This can occur when the spot size on the sample becomes smaller as the laser beam travels more obliquely through the optical system.

\section{Uniform Cell Scanning - Verification of the Calculated Predictions}

Solar cell A of the test pattern was fabricated to be free of any intentional defects. Iine scans of the laser spot between metallization lines should thus produce photoresponse curves whose shape is predicted by eq (5). Figure 14 shows a family of these curves for different attenuation lengths normalized to metallization spacing. As will be shown in eq (10), the attenuation length is inversely proportional to the square root of the short circuit current of the illuminated cell. For the low levels of light intensity used in this work, the short circuit current is linearly related to the iight bias. Thus, the attenuation length is also inversely proportional to the square root of the light bias. Line scans of cell A with different levels of light bias are shown in figure 15. The amplification of the laser-induced photoresponse was increased progressively with increasingly greater light bias in order to have the curves of comparable height on the display. The general agreement between the two sets of curves is apparent.

\subsection{Measurements and Analysis}

To obtain a more quantitative measurement of the agreement between the predicted and measured curves, three approaches were used to determine the attenuation length, $x_{0}$.

The first method, suggested by Sawyer and Kessler [3], is based on the calculated ratio of the minimum photoresponse when the laser spot is midway between metallization lines to the maximum when the spot is directly adjacent to a line:

$$
\frac{V_{\min }}{V_{\max }}=\operatorname{sech}\left(\frac{\ell}{2 x_{0}}\right)
$$

This expression follows directly from eq (1). The ratio $\frac{V_{\text {min }}}{V_{\max }}$ was taken

directly from the photoresponse curves. The average values of $v_{\max }$ at the right and left sides of the scan were taken in order to reduce the effects of small asymmetries. Values of $x_{0}$ at various levels of background bias illumination are given in column 4 of table 2 and column 3 of table 3 for measurements on wafers 1 and 2, respectively. The data for table 3 were all taken near the center of the cell.

The second approach to the measurement of $x_{0}$ uses a computer curve fit of eq (4) to the data with $x_{0}$ as the adjustable parameter. The photoresponse line scan data were carefully digitized using a trace on the $x-y$ recorder. 


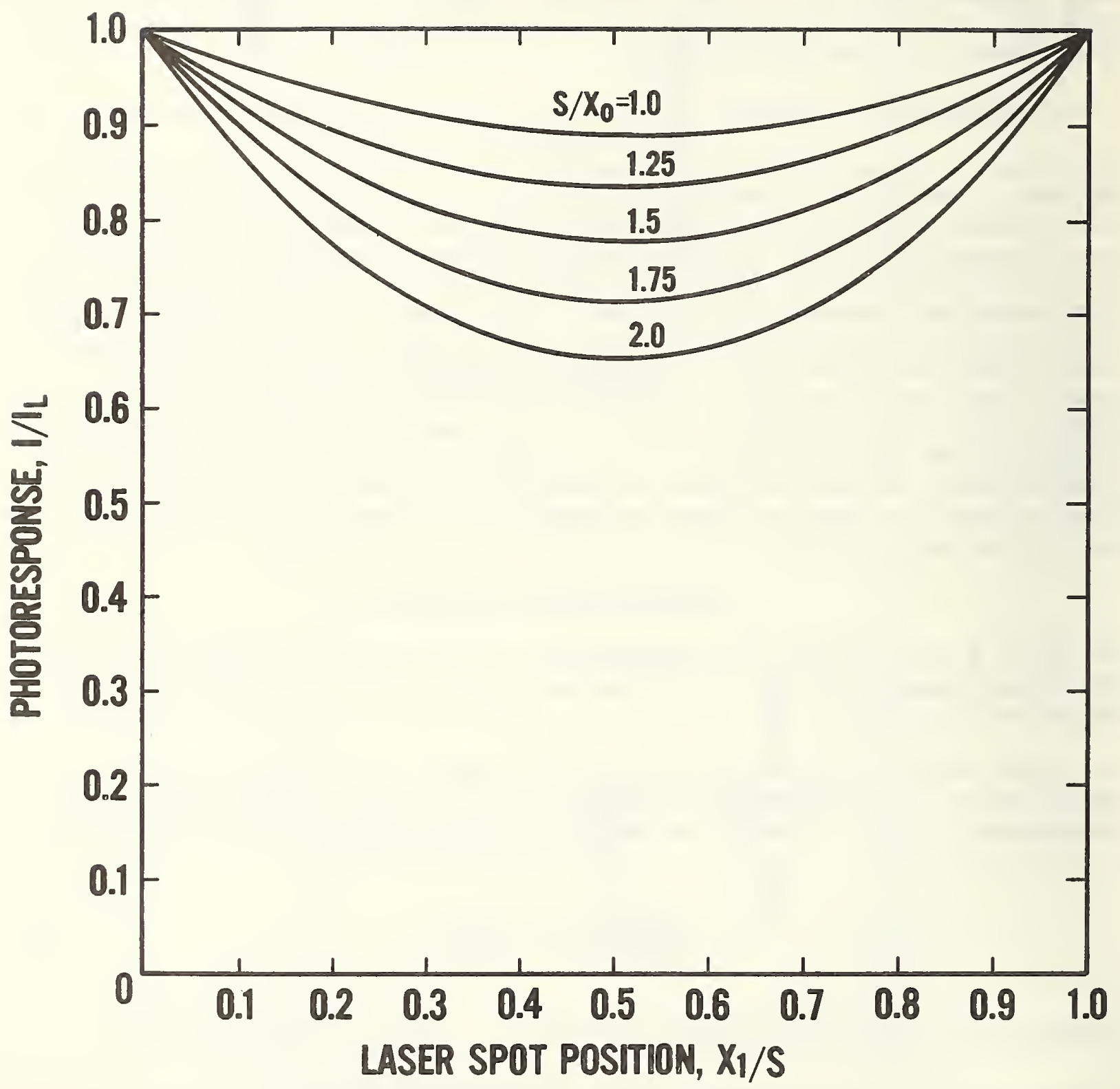

Figure 14. Calculated photoresponse of a uniform cell to a laser spot for different attenuation lengths, $x_{0}$, expressed in terms of metallization spacing $\mathrm{S}$, between metallization lines at $\mathrm{x}=0$ and $\mathrm{x}=1$. 


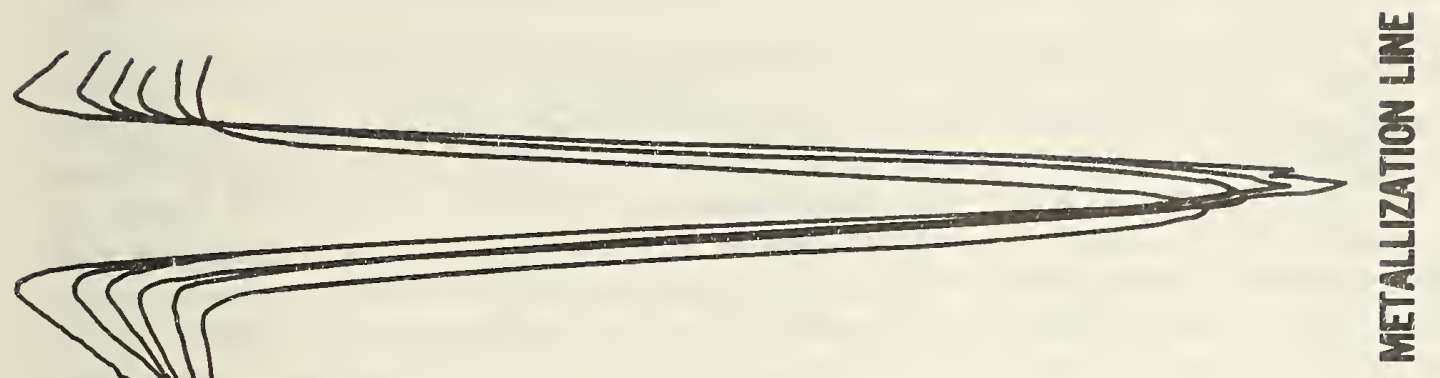

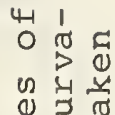

ข

$\pi+n$

थ 0

द 3

त 1

일

N

-

त्-

+

(2) 3

E 0

E $>0$

(1) 너

(1) 5

㟧 4

Q

E 0

थ

o 1

U

.

0

- 50

ન- न्न

E

○先要 + 다 닽. 0 थ न-1 걷 $\infty 0 . r 1$.

E U

글

प्र न है है

पे

(1) (1) था

थ 50

0 ,

Qस ह

of 0 \%

叫些

$0-1$ o

$0>n$

हैत

$0+4$ ?

Q 50

400

उ 5

in $0=0$

10

04 ह

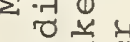

ro

- 4

$\pi$ प थ 0

$0 \ll 3$ б

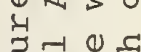

क्ना प्ञा

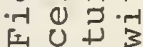


Table 2. Attenuation Lengths Measured on Uniformly Diffused Solar Cell A of Wafer 1.

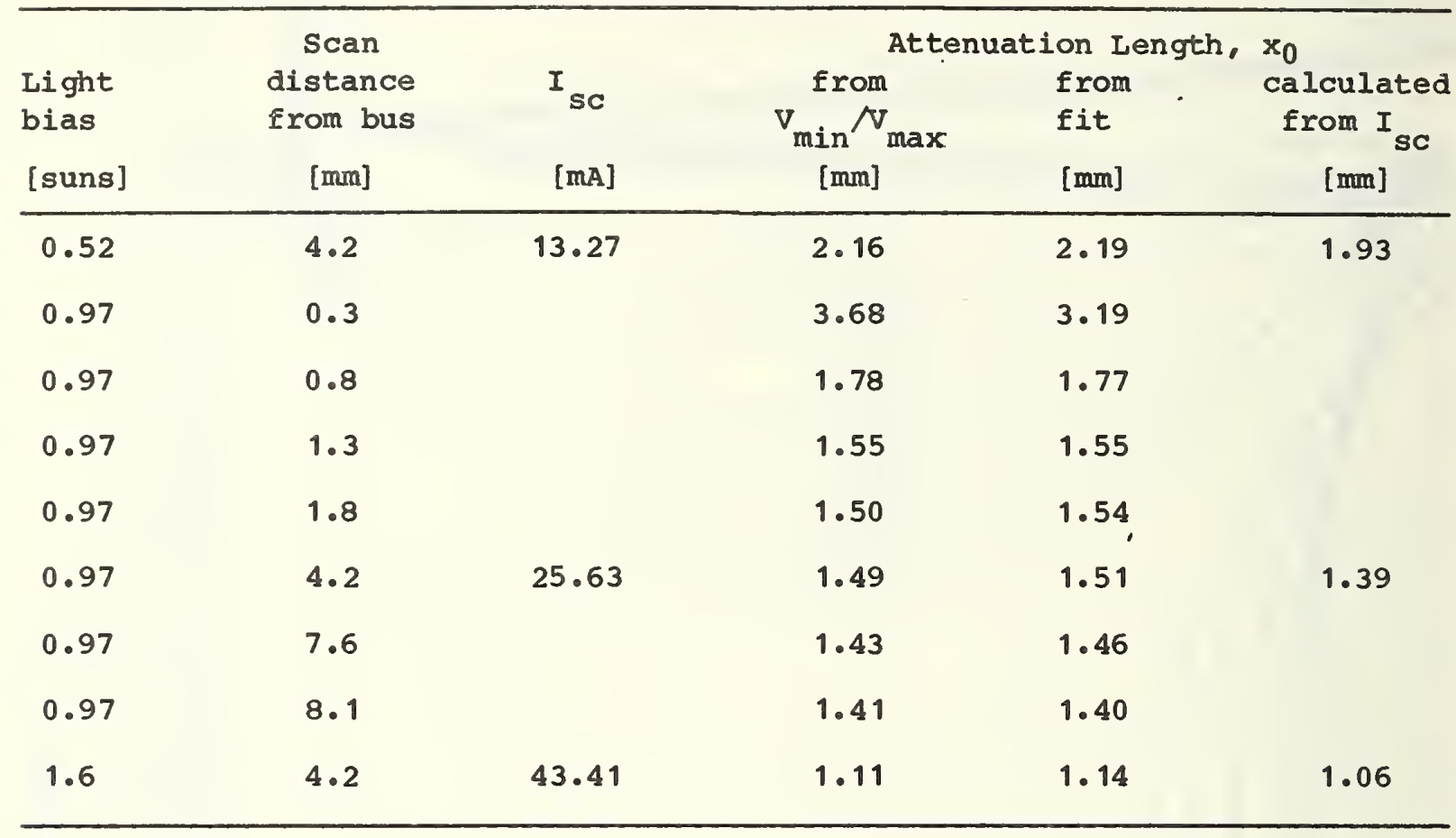

Table 3. Attenuation Lengths Measured on Uniformly Diffused Solar Cell A of Wafer 2 (all scans in center of cell).

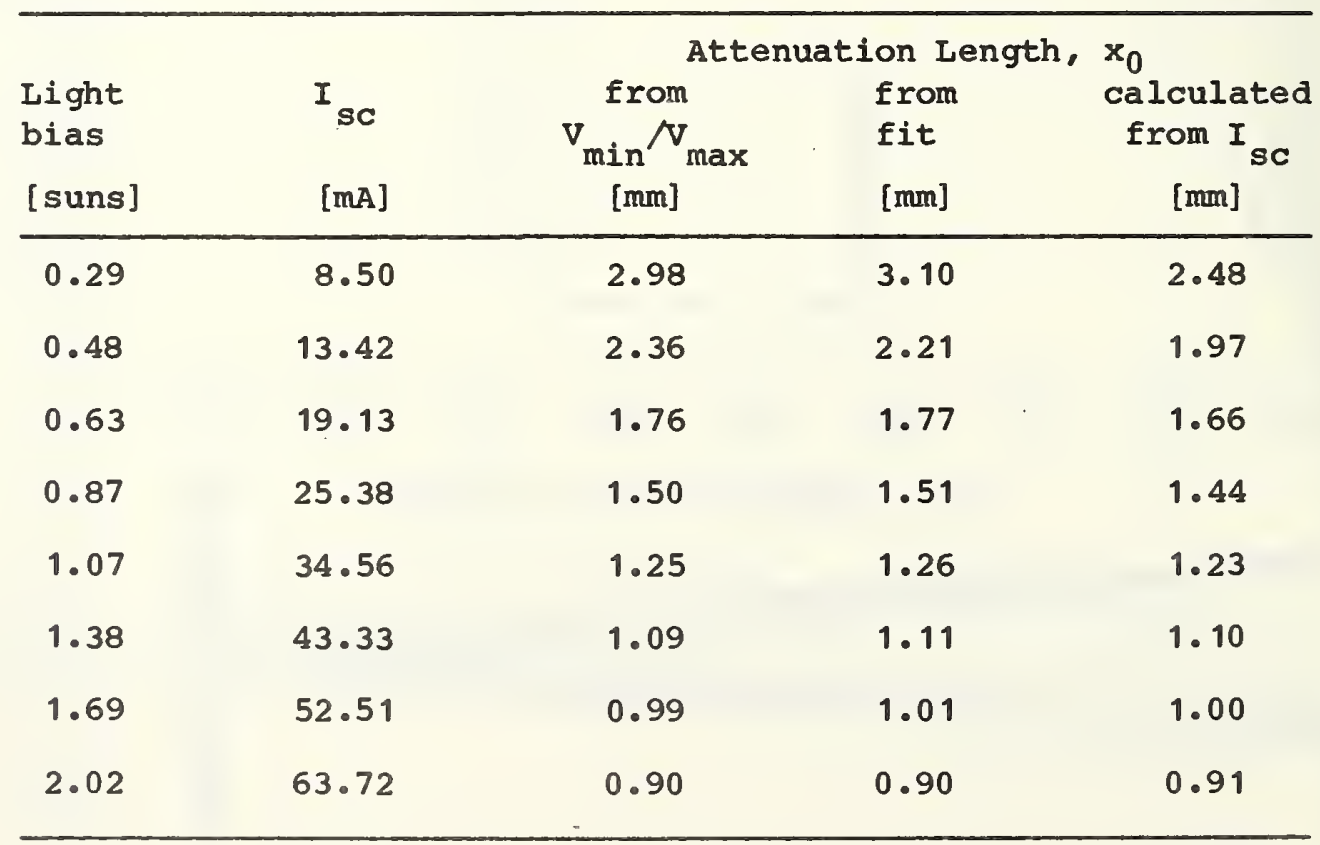


least squares fitting procedure was then used to minimize the conventional chl squared statistical parameter by adjusting $x_{0}[8]$. Figure 16 shows an example of the data $\mathrm{as} \mathrm{x}^{6} \mathrm{~s}$ and the values from the equation as dots. A careful inspection of this figure shows a slight deviation between the line scan data and the calculated curve near the right-hand metallization line. This is an indication of a small asymmetry in the line scan data due to a slight nonuniformity in light bias over this region of the cell as discussed in section 3. The effect on the determination of $x_{0}$ is small, however, since the value of $x_{0}$ is determined by the fit over the whole curve. The results of this analysis are shown in column 5 of table 2 and column 4 of table 3.

The third method of obtaining a value of $x_{0}$ uses eq (5) and the average small-signal diode conductance per unit area, $\mathrm{z}^{-1}$, over the whole solar cell. To obtain an expression for $\mathrm{z}^{-1}$, consider the equation for the cell current density $j_{L}$ due to steady-state illumination $[3,6]$ :

$$
j_{I}=j_{0}\left(e^{\frac{q V}{m k T}}-1\right) \text {. }
$$

where $j_{0}$ is the cell saturation current density, $v$ is the cell voltage, $m$ is the quality factor of the cell, $k$ is the Boltzman constant, and $T$ is the absolute temperature.

The small-signal diode conductance per unit area is the differential of the current density $j_{L}$ with respect to the cell voltage $v$ :

$$
z^{-1}=\frac{d j_{L}}{d v}=\frac{g}{m k T}\left(j_{L}+j_{O}\right) .
$$

The forward light-biased current, $j_{L}$, is much larger than $j_{0}$ and

$j_{I}=\frac{I_{S C}}{A}$ where $A$ is the active cell area, and $I_{S C}$ is the short circuit current. We can then write:

$$
\mathrm{z}^{-1}=\frac{\mathrm{q}}{\mathrm{AmkT}} \mathrm{I}_{\mathrm{sC}}
$$

We then have:

$$
x_{0}=\sqrt{\frac{z}{\rho}}=\sqrt{\frac{A m k T}{\text { II }_{\text {sc }}^{\rho}}} .
$$

The quality factor, $\mathrm{m}$, for our cell was obtained by a least squares computer fit to the dark I-V curve using the expression:

$$
I=I_{0}\left[\exp \left(\frac{q\left(V_{j}-R_{S} I\right)}{m k T}\right)-1\right],
$$

where the cell voltage, $v$, of eq (7) is expressed as the junction voltage, $v_{j}$, minus the voltage drop across the cell series resistance, $R_{S}$. The value of $\mathrm{m}$ from this method is $3.21 \pm 0.01$ for cell $\mathrm{A}$ of wafer 1 and $1.20 \pm$ 0.01 for cell A of wafer 2. The factor $\mathrm{kT} / \mathrm{q}$ is $25.4 \mathrm{mV}$ for a temperature of $21^{\circ} \mathrm{C}$, which was assumed to be the cell temperature for all the data collected. This, however, introduces a small systematic error in the results as the cell temperature is expected to increase with greater light bias. To esti- 


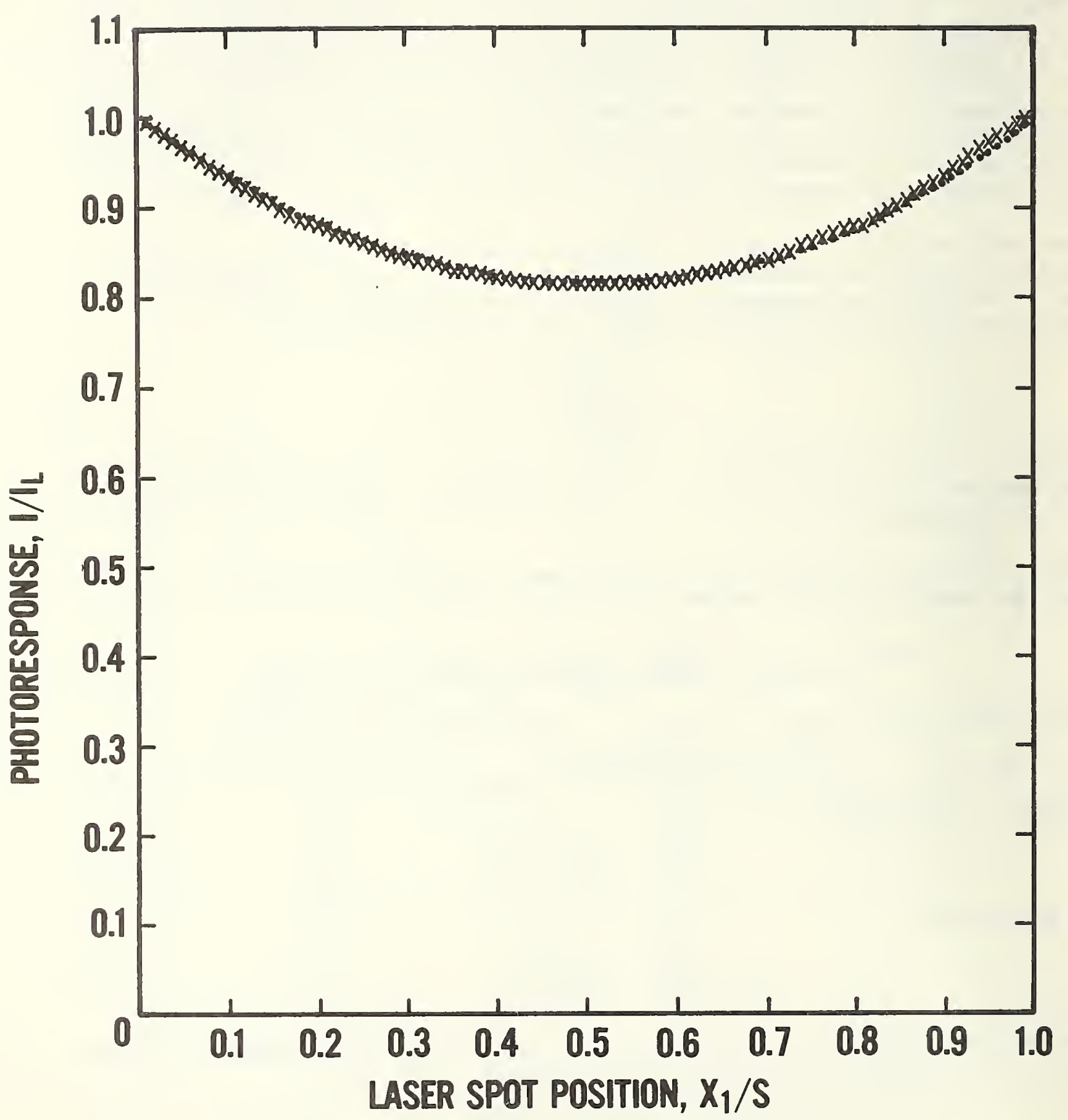

Figure 16. Curve fitting of eq (4) (dots) to photoresponse line scan data (X's) between metallization lines by minimizing chi squared. The illumination level was 1.6 suns on cell A of wafer 1 . 
mate the magnitude of this effect, the surface temperature of cell D was measured with a calibrated thermocouple under a light bias of approximately one sun. A temperature rise of $5^{\circ} \mathrm{C}$ was observed at equilibrium corresponding to 1.7-percent error in the calculation of $x_{0}$. This suggests that a temperature sensor incorporated into the solar cell test pattern would be useful in making more accurate measurements as discussed in section 7.4. The active area of each cell is $84.3 \mathrm{~mm}^{2}$. The area of the cell was calculated from the design measurements on the photomasks for the solar cell test pattern. The dimensions were checked by direct measurement with a microscope and the photoactivity over the entire cell was verified with the laser scanner. The values of $x_{0}$ given in column 6 of table 2 and column 5 of table 3 are obtained from eq (10) with the use of the above values for $\mathrm{m}, \mathrm{kT} / \mathrm{q}$, and $\mathrm{A}$ along with directly measured values of short-circuit current, and the average values of $\rho$ from the reference test structure.

These data from each of the three determinations of the attenuation length, $x_{0}$, are plotted in figures 17 and 18 where the calculated values of $x_{0}$ obtained from $I_{S C}$ are shown with a smooth curve to guide the eye. The values obtained from $v_{\min } / v_{\max }$ and the curve fitting of the analytical expression to the photoresponse data are shown as squares and circles, respectively. The overall agreement is satisfactory when the assumptions on which the calculations are based are met as discussed in the next section.

\subsection{Regions of Validity}

It should be noted that when scans are taken very near the bus electrode, the assumption of infinitely long parallel electrodes made in deriving eqs (3) and (4) is not valid. The photoresponse curves are much flatter near the bus electrode, producing incorrectly large values for the attenuation length as can be seen in the second and third rows of data in table 2. At the opposite side of the cell near the ends of the metallization line, the opposite effect occurs as charge collection is reduced, making the curvature greater than predicted. These effects are seen clearly in figure 19 as the measured values for $x_{0}$ increase markedly for measurements near the bus bar and decrease somewhat as measurements are made close to the end of the metallization lines. The data used, listed in table 2, was taken at a light bias level of approximately 0.97 suns overall illumination corresponding to an attenuation length which is very close to the intermetallization spacing of $1.5 \mathrm{~mm}$. Thus, the curve in figure 19 suggests that the determinations of attenuation length by the techniques of the previous section are consistent within \pm 4 percent as long as the line scan is not made within one attenuation length of the bus bar or metallization ends of the cell.

The poor agreement between the values of $x_{0}$ at low levels of light in tables 2 and 3 is also due to the attenuation length being long compared to the distance between the line scan and the bus bar although the scan is near the center of the cell. This again violates the assumption of current collection only by the metallization lines and the data reflect the flattening effect of bus bar collection on the curvature of the line scan.

Thus, the agreement obtained between the three determinations of attenuation length suggests the calculated photoresponse predictions can be used with confidence when the attenuation length is sufficiently short to meet the con- 


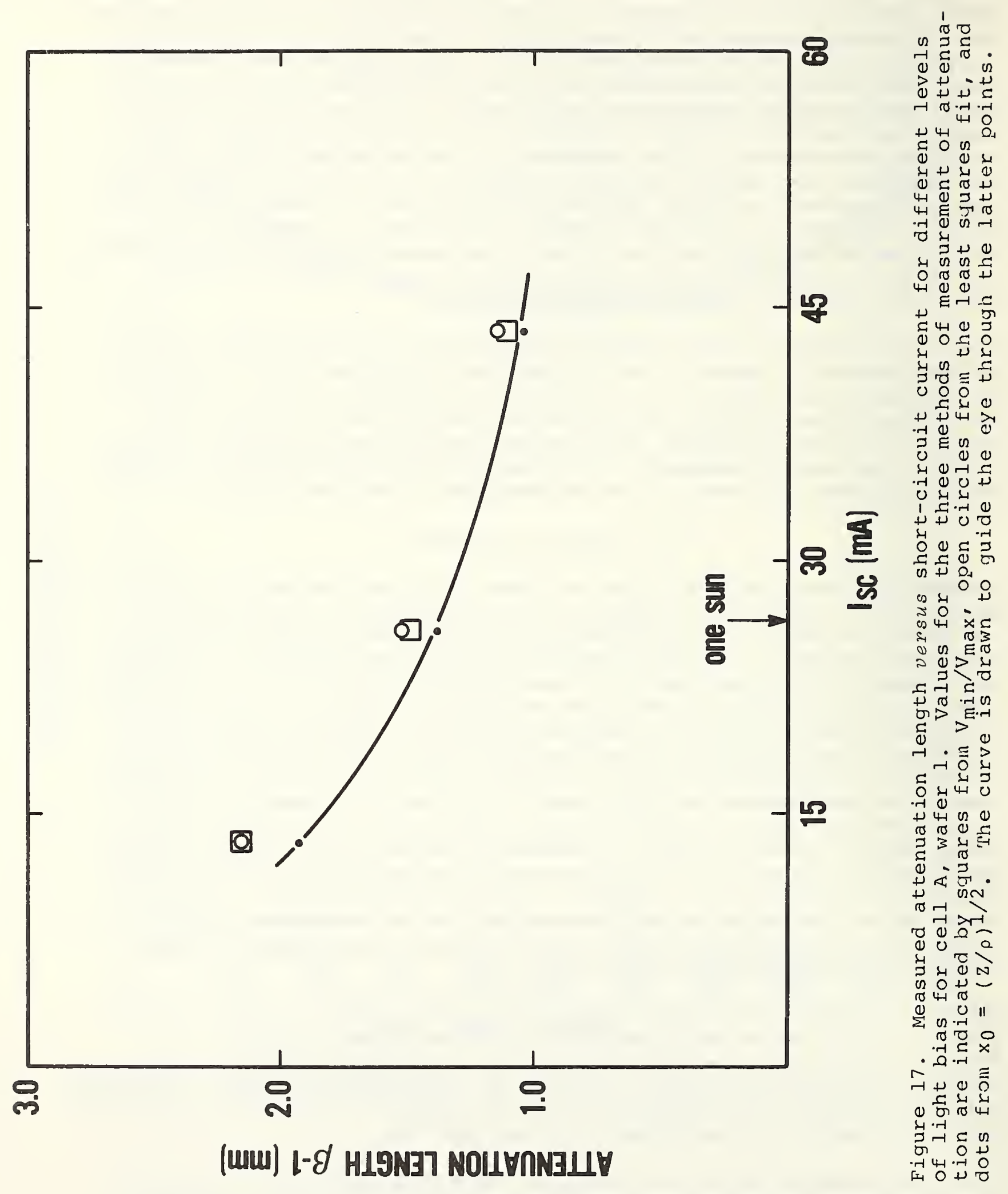




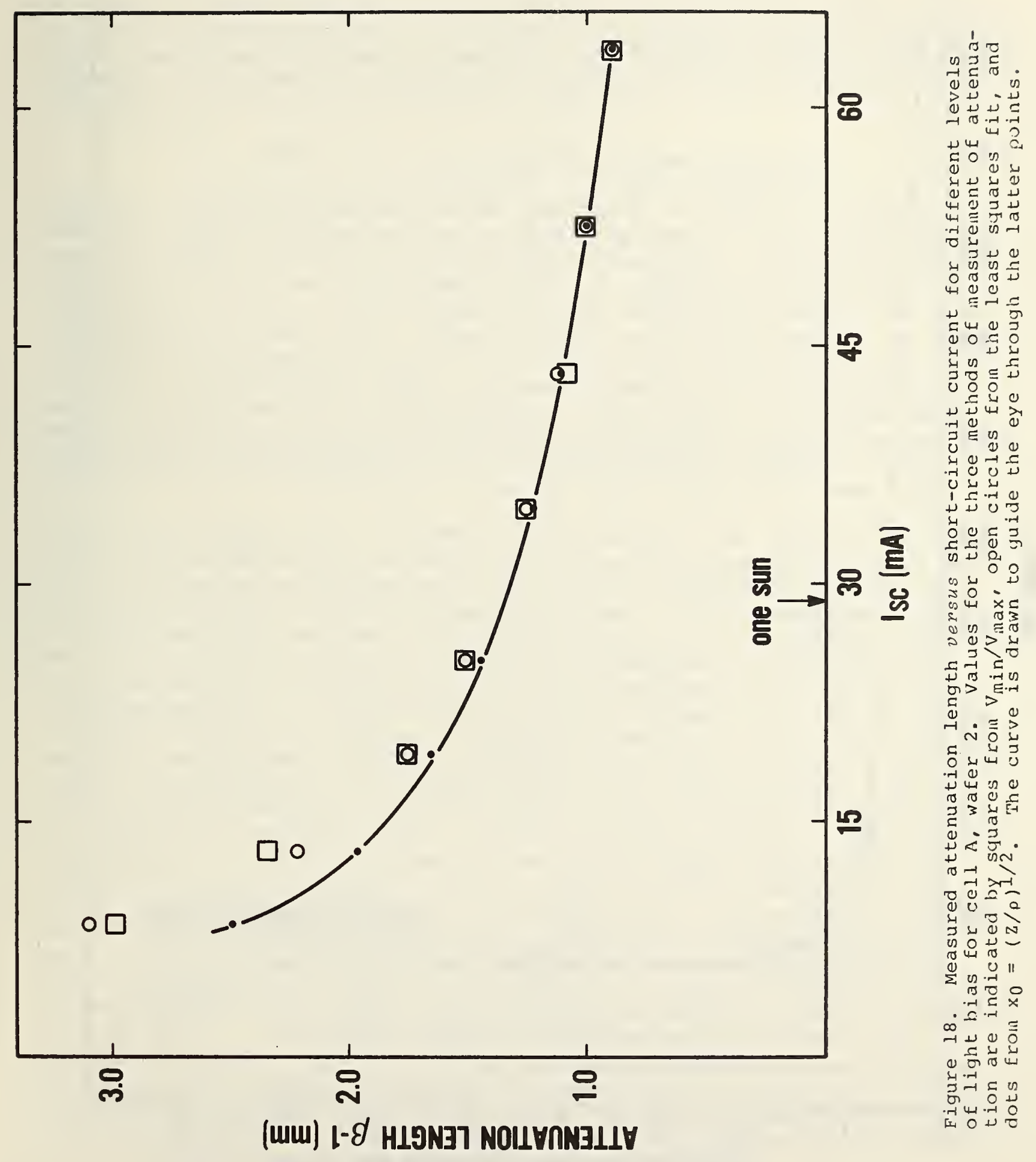




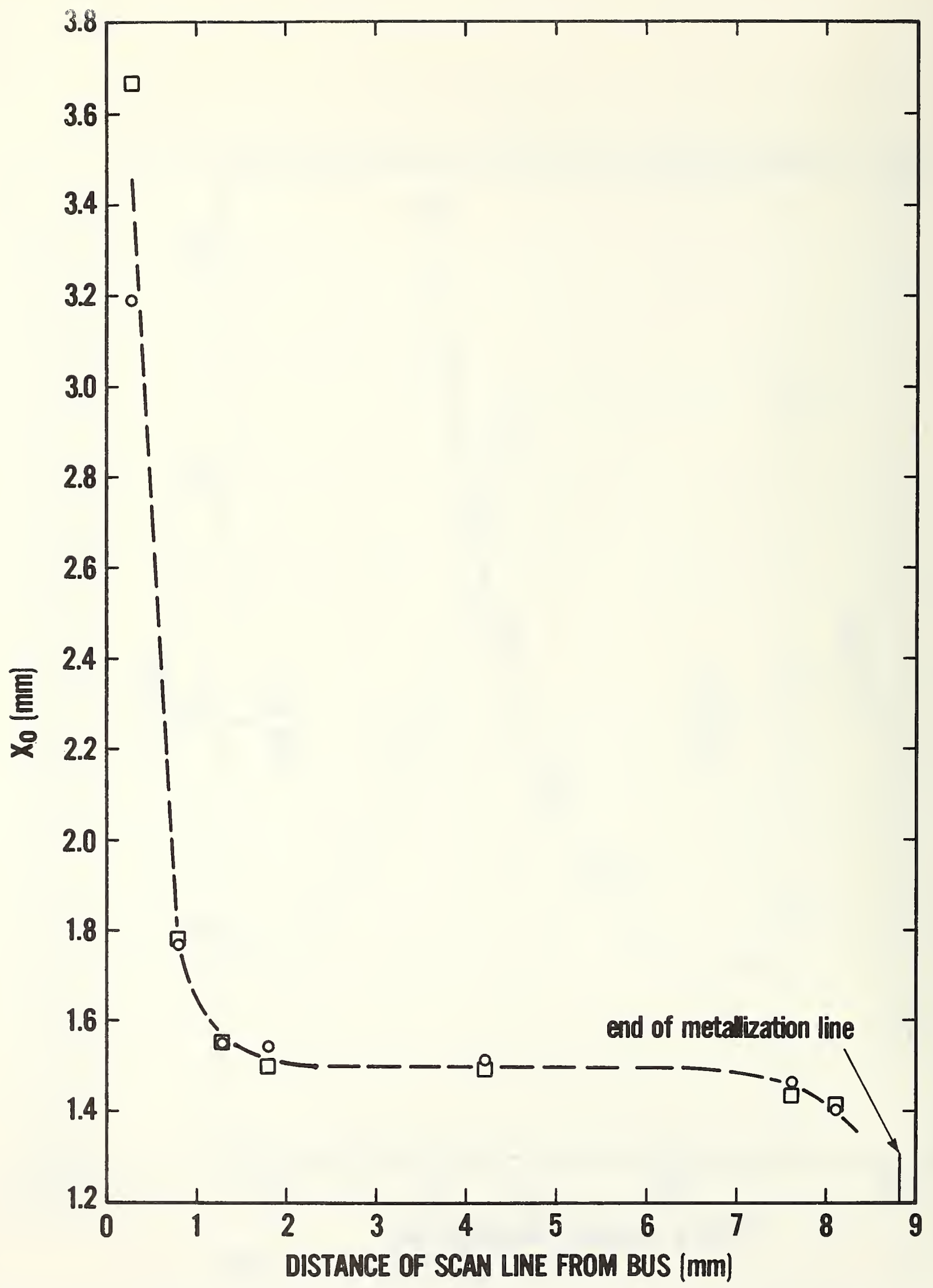

Figure 19. Plot of measured attenuation lengths $x_{0}$ from table 2 for 0.97 suns illumination versus distance of the line scan from the solar cell bus bar, at $\mathrm{x}=0$, indicating the region between 2 and $7 \mathrm{~mm}$ over which the predictions of eqs (3) and (4) are valid. Data points squares and open circles are for $x_{0}$ determined from $v_{m i n} / V_{\max }$ and from the least squares fit, respectively. The dashed line is meant to guide the eye through the data points. 
ditions which the calculations were made. The actual values depend on the geometry of the cell being tested.

It should be emphasized that the measurements and calculations used in this section assume a uniform cell. If there are variations in sheet resistance between metallization lines (as studied in the following section), the measurements of attenuation length may be considered to be an average value determined by the charge flow across the cell.

\section{Detection of a Step Change in Sheet Resistance}

Numerical calculations by Lehovec and Fedotowsky [9], using the geometry of cell $C$ in figure 1, indicated that step-wise changes in sheet resistance of less than about two-to-one would be barely discernible, and then only if the attenuation length were sufficiently short in comparison with the metallization spacing, $S$ (i.e., if the light bias were sufficiently great). This is illustrated in figure 5 for a value of about 1.46 for the ratio of the sheet resistance of the central $\left(\rho_{2}\right)$ to that of the side $\left(\rho_{1}\right)$ regions. Even where the ratio of attenuation length $x_{0}$ to metallization spacing is 0.4 , the change in curvature of the photoresponse is only slight as the light probe moves across the step-wise change in sheet resistance. The basic reason for this is the averaging effect of the two sheet resistance regions on the carrier flow to the metallization lines on either side of the laser spot.

A line scan of solar cell C of NBS-22 (wafer number 1) is shown in figure 20. Ignore for the moment the increase in the level of photoresponse in the central region which is believed to be due to the difference in junction depth for the regions with different sheet resistance. The photoresponse curve was digitized using 100 data points as shown in figure 21. A computer routine was used to select values for $x_{0}$ which would separately provide the best fit of the data to the function given by the numerator of eq (5) for each of the three regions. The curves giving the best agreement with the digitized data are shown as line segments in figures 22 and 23 for the left and central portions, respectively, with $X$ 's representing the data, and dots the computed curve. Figure 24 shows the computed curve for all these regions. The central region was lowered to align the three curves. As may be observed, were the curves to be connected, there would be no obvious change in the nature of the curve. The best $x_{0}$ values for each of the three segments were essentially indistinguishable; values for $x_{0}$ for the left, center, and right section were $1.22,1.20$, and $1.29 \mathrm{~mm}$, respectively. This result is not unexpected from the numerical results shown in figure 5. For the light bias used, a value of only about 0.9 was obtained for the ratio of attenuation length to metallization spacing, as judged by the best-fit values of $x_{0}$. It is possible that with greater light bias and the resultant greater curvature in both regions, a noticeable change in curvature could have been seen. A sufficiently intense light source with the required uniformity was not available to do this, however. The ratio of sheet resistances, $\rho_{2} / \rho_{1}$, for the cell tested is somewhat larger ( 1.6 times) than for the case shown in figure 5. This would serve to accentuate only slightly any differences in curvature of the photoresponses in the two regions shown.

The experimental results, illustrated in figures 21 through 24, show that the scanner technique is not sensitive to step changes in sheet resistance due to 


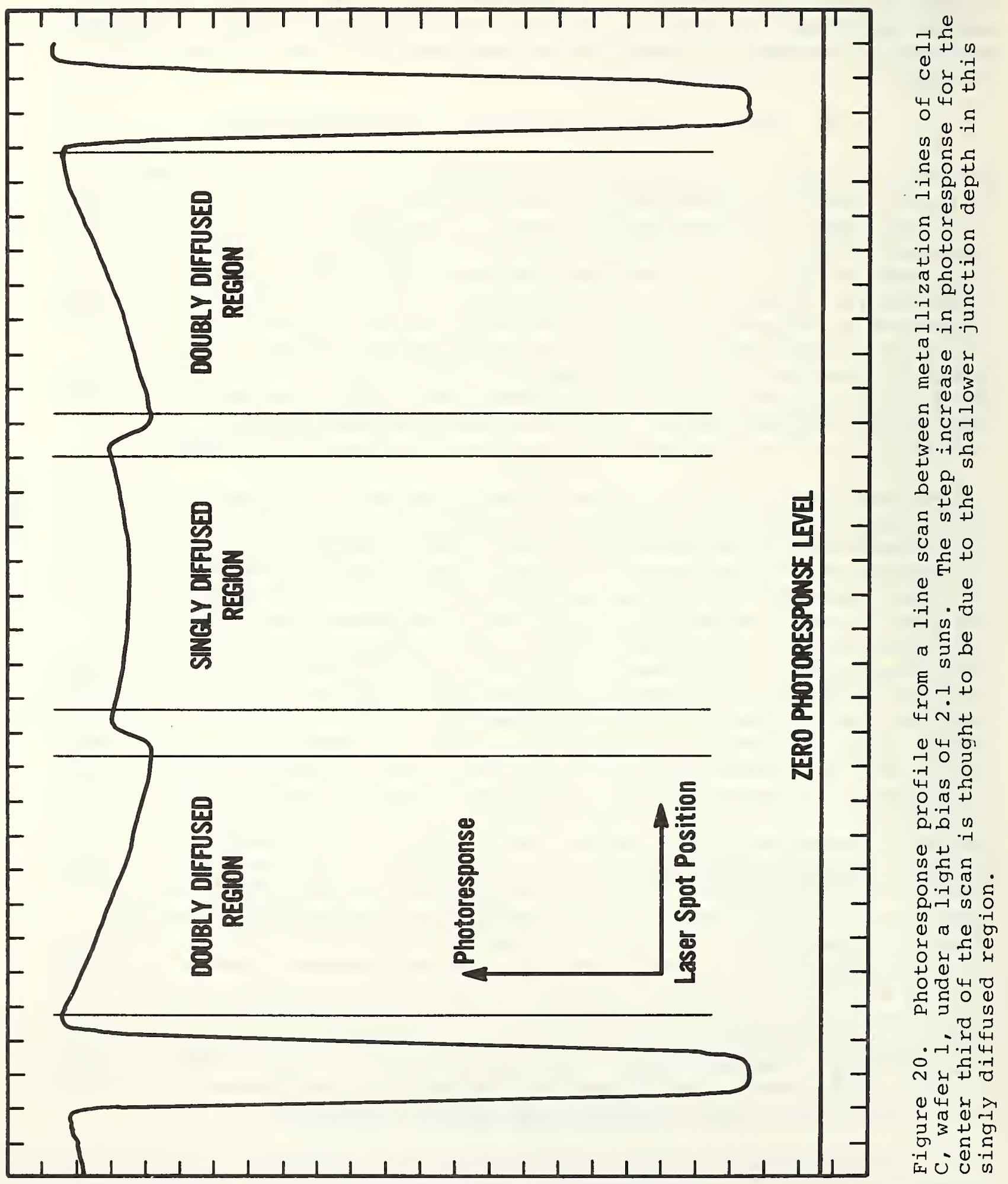




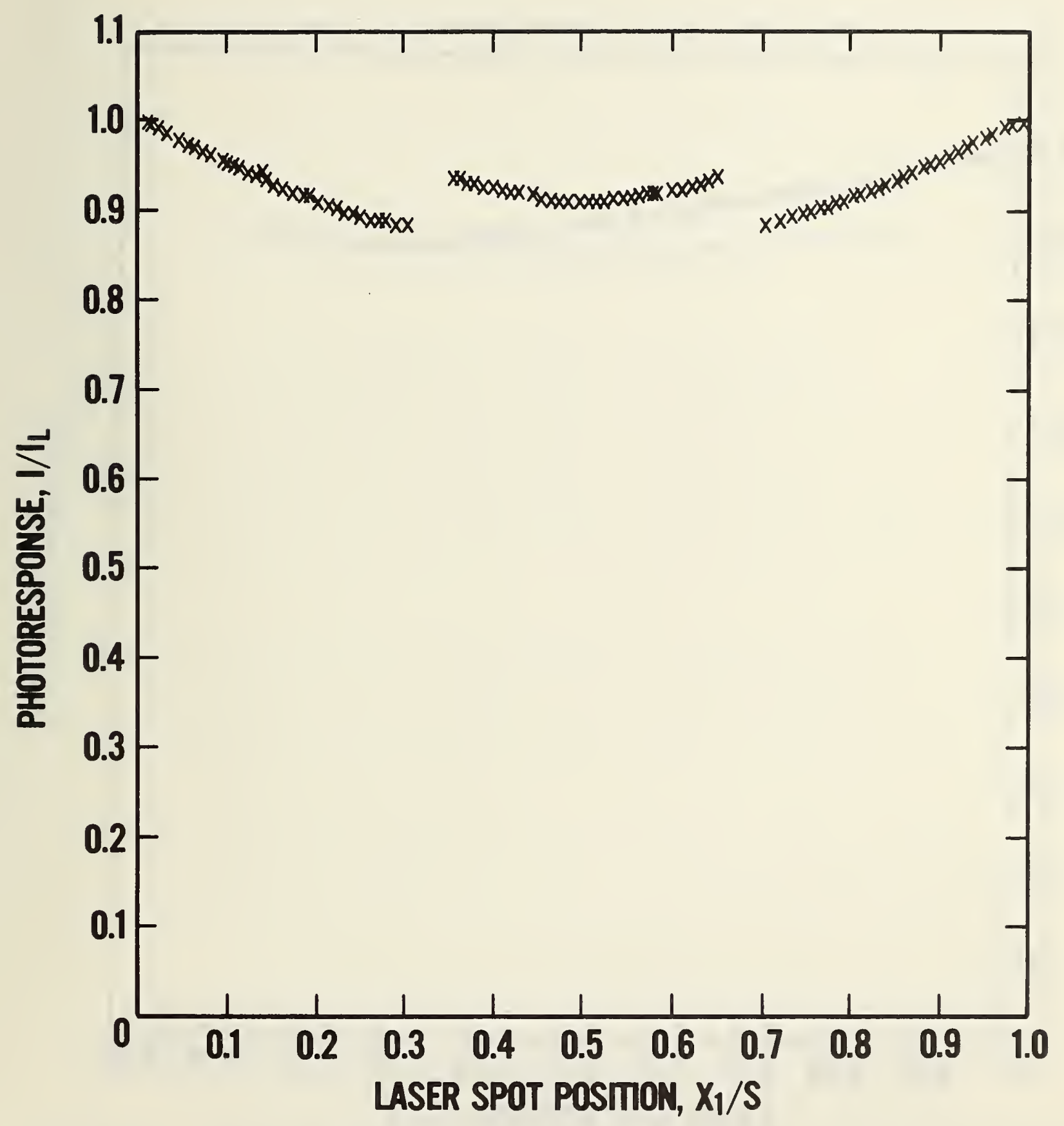

Figure 21. Digitized photoresponse data from a line scan between metallization lines of cell $C$, wafer 1 . The transition regions between singly (center) and doubly (sides) diffused regions are not included. 


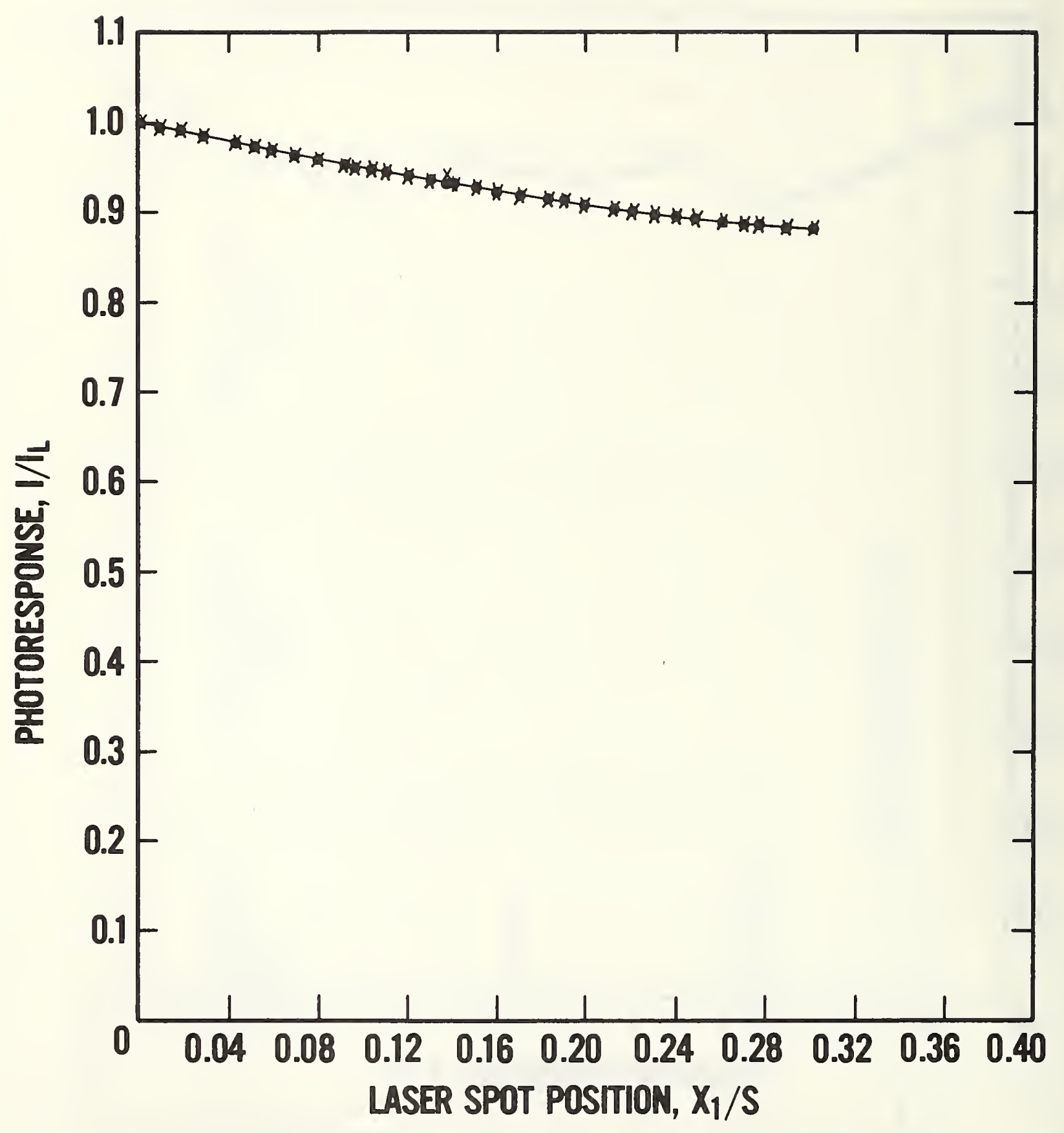

Figure 22. Left portion of the photoresponse data shown in figure 21 where the line scan data are shown as $X^{\prime}$ 's and computed points fron a best fit adjustment of attenuation length, $x_{0}$, are shown by dots. 


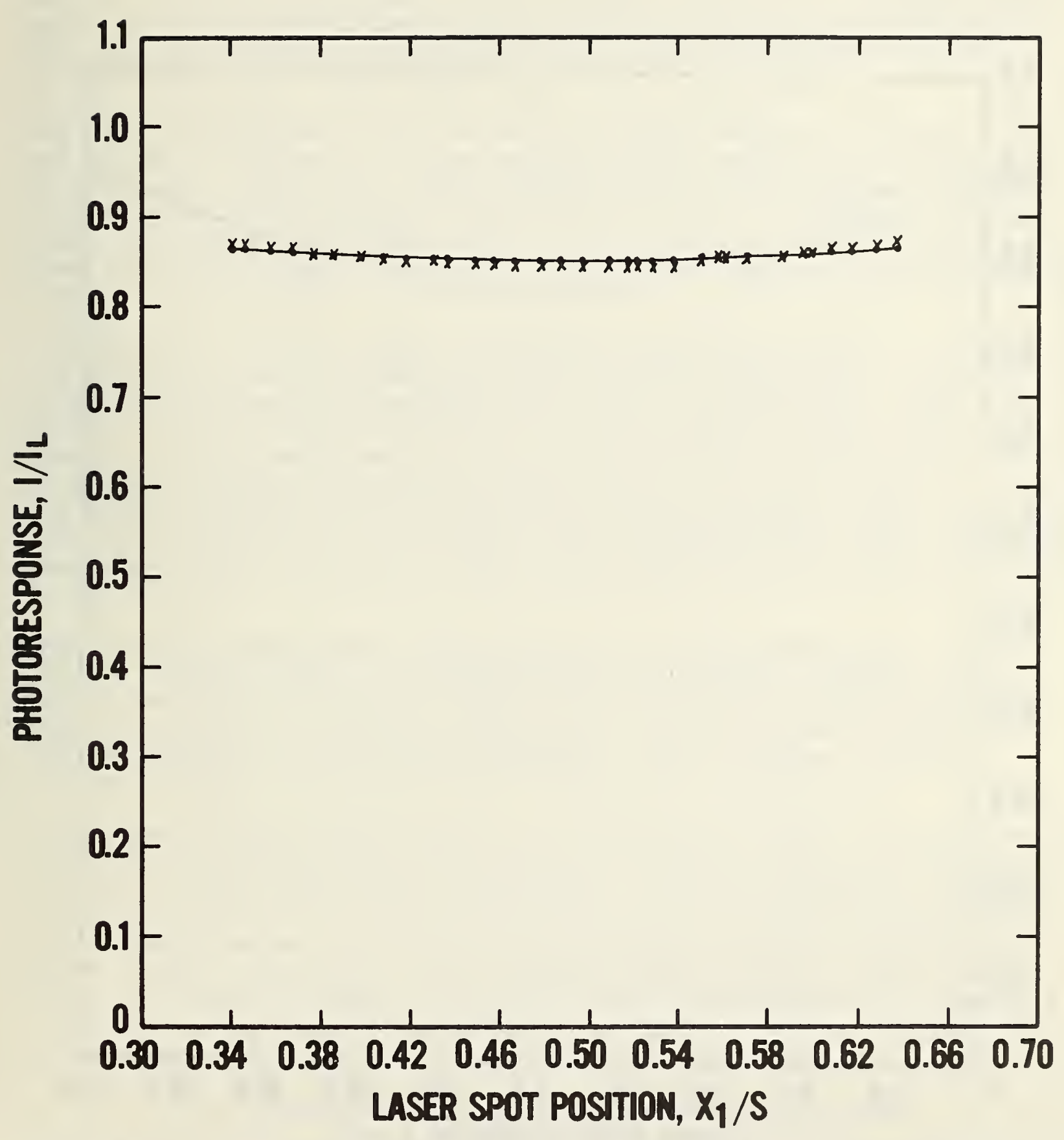

Figure 23. Central portion of the photoresponse data shown in figure 22 where the line scan data are shown as X's and computed points from a best fit adjustment of attenuation length, $x_{0}$, are shown by dots. 


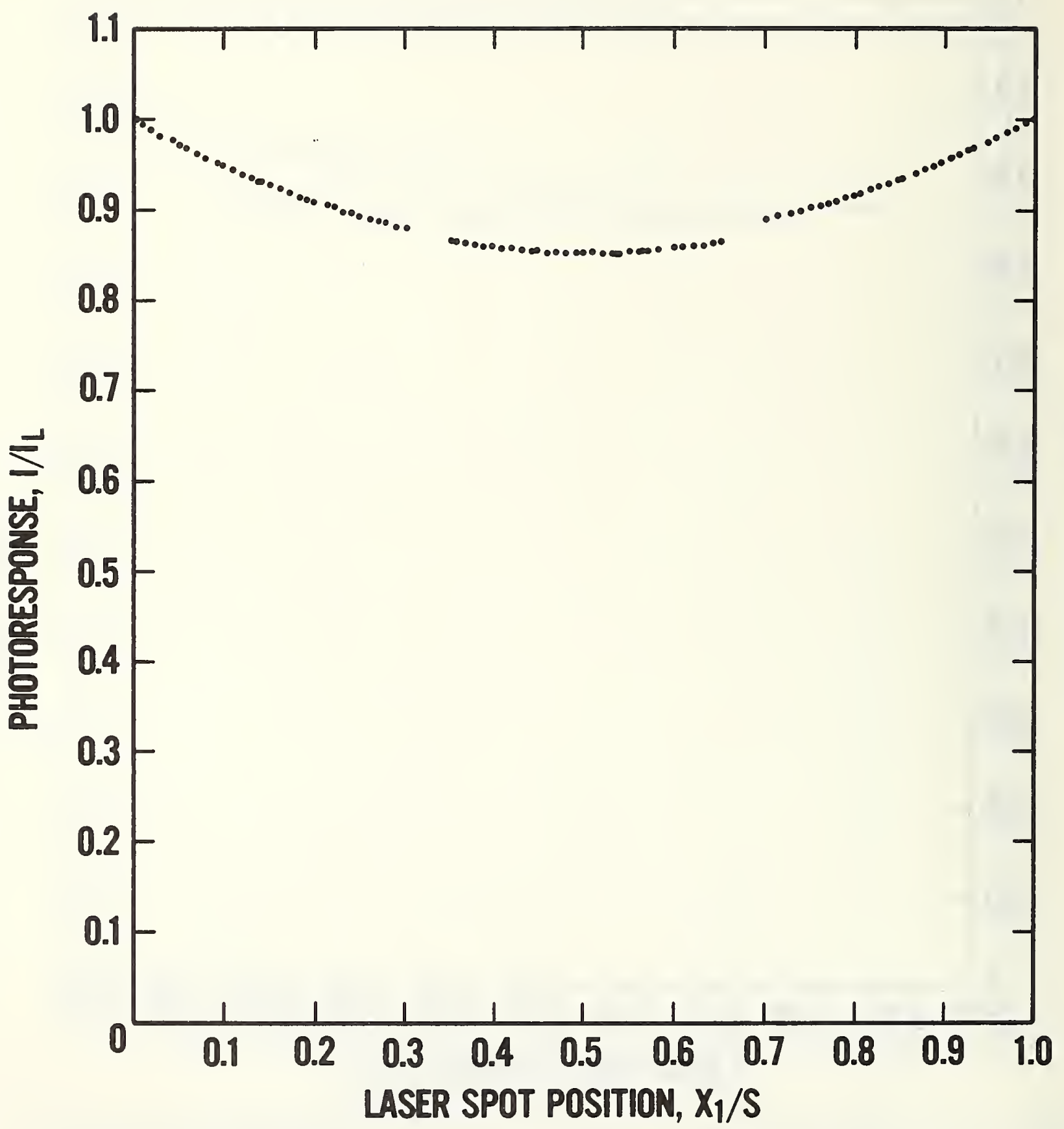

Figure 24. Complete fitted photoresponse curve with superimposed data from figure 22 where the central portion has been lowered for comparison between the three regions. 
dopant density changes, unless quite large changes in sheet resistance exist and perhaps rather intense light bias is used. This is in agreement with the work of Lehovec and Fedotowsky [9] for the case where $\rho_{2} / \rho_{1}$ is greater than unity, as is the present experimental situation. Their calculations also show that the technique is more sensitive to detecting changes of sheet resistance when $\rho_{2} / \rho_{1}$ is less than unity.

The lower photoresponse level observed in the side regions, as shown in figure 10, may be explained by these regions having a deeper junction than the center region. The loss of photogenerated carriers to recombination generally decreases with decreasing junction depth [10] in the range of junction depths applicable to the NBS-22 cells (i.e., $\left.\sim_{0.6} \mathrm{\mu m}\right)$. Hence, the side regions would have greater losses and, consequently, lower photoresponse levels than the center region.

A difference in junction depth is expected because of the order in which the two diffusion masks were used in the wafer fabrication process. One mask leads to the exposure of the entire cell area to the phosphorus dopant, the other to only the regions adjacent to the metallization stripes (the side regions). In the present NBS-22 cells, the latter mask was used first. In this case, the junction forms and advances only in the side regions. During the second diffusion step, the junction forms and advances in the rest of the cell, while the junction in the side regions proceeds still deeper. The net result is a deeper junction in these side regions than in the central regions of the cell.

Based on these observations, the experimental results suggest that differences in junction depth can be detected with the scanner technique. Such differences can also complicate the analysis of cells with variations in sheet resistances. It is also expected that certain changes in dopant profile and density could affect photoresponse, with or without a change in sheet resistance, as was mentioned by Lehovec and Fedotowsky [9].

Step changes in sheet resistance with no significant change in junction depth can be achieved by reversing the sequence of the two masks used. In this case, the junction first forms and advances over the entire cell. It will continue to advance uniformly over the cell during the second diffusion step as more dopant atoms are introduced into the side regions to increase the dopant density and produce a net increase in sheet resistance there. To detect and study how dopant profiles can affect photoresponse, one could fabricate these cells with the process just described or with an ion implantation process.

\section{Detection of Noncontacted Metallization Regions}

Solar cell B in the NBS-22 test pattern was fabricated to have controlled regions where the top surface metallization does not make electrical contact to the cell emitter but is insulated from it by a silicon dioxide layer, as illustrated in figure 3. This condition would simulate contact liftoff, a typical degradation mode. The lengths of the breaks range from 25 to $1600 \mu \mathrm{m}$, with each successive length doubling from the smallest to the largest. Lehovec and Fedotowsky have shown that the photoresponse curve approaches zero slope as the laser spot is scanned across a break in the metallization 
contact in marked contrast to the steep slope near a normal contact [5] as shown in figure 6 . The phenomenon is illustrated in figure 25 for a 800- $\mu \mathrm{m}$ break in metallization with the illumination level producing an attenuation length of approximately $450 \mu \mathrm{m}$. The photoresponse is very flat for the fourth, fifth, and sixth scans from the top, indicating the region of the break. The third and seventh scans from the top show the characteristic slope associated with the laser spot approaching good metallization contact.

A photographic study was made to determine how small a break could be detected with the laser scanner operated in the raster scan mode as described in earlier reports $[2,4]$. Indications of a break in metallization contact are shown in figure 26 and for 800-, 400-, and 200-pm breaks, respectively, also for a 450- $\mu \mathrm{m}$ attenuation length. The metallization runs diagonally across the photograph from upper right to lower center. Figures 26a and 26b clearly show the region of a break over the major center portion of the photograph. Figure 26c shows the limit of detection, to a careful observer, at the 200- $\mu \mathrm{m}$ wide break. The shorter breaks were not detected. A rough guideline is then that the minimum break detectable is approximately equal to one-half of the attenuation length in the cell.

The use of the slope of the photoresponse line scan to detect areas of noncontact of the metallization lines on solar cell emitters is limited by the attenuation length one can achieve by light biasing the cell. A large light bias is desirable to decrease the attenuation length and thus to increase the curvature of the line scan approaching good metallization contact in order to distinguish it from the relatively flat scans across areas of no contact. The small attenuation length also enhances detection of smaller breaks because if the attenuation length is comparable to or larger than the break length, the photocurrent collection will be unimpeded by the break.

A more careful study of the precise line shape in the vicinity of a break would require a very accurate stepping motor and controller to position the solar cell accurately at a predetermined spot under the laser spot since the size of the defects under consideration is too small for direct visual alignment. As discussed in section 8 , this addition to the laser scanner is considered vital to making more accurate measurements.

\section{Factors to Consider in the Redesign of the Solar Cell Test Pattern}

The solar cell test pattern, including the reference test structures, was designed to aid in application of the laser scanner to the measurement of solar cell operating parameters and their relationship to the appropriate material parameters. This pattern has proved useful for this purpose, and its potential in determining the capability of a laser scanning system to detect certain solar cell defects has been demonstrated. However, based on experience in using the pattern, several improvements and modifications that would enhance its usefulness and expand its capability can be suggested as discussed in the following four sections.

\subsection{Cell Configuration and Mounting}

The present solar cell test pattern contains four different solar cells fabricated on the same wafer, each surrounded by 16 replicas of the reference 


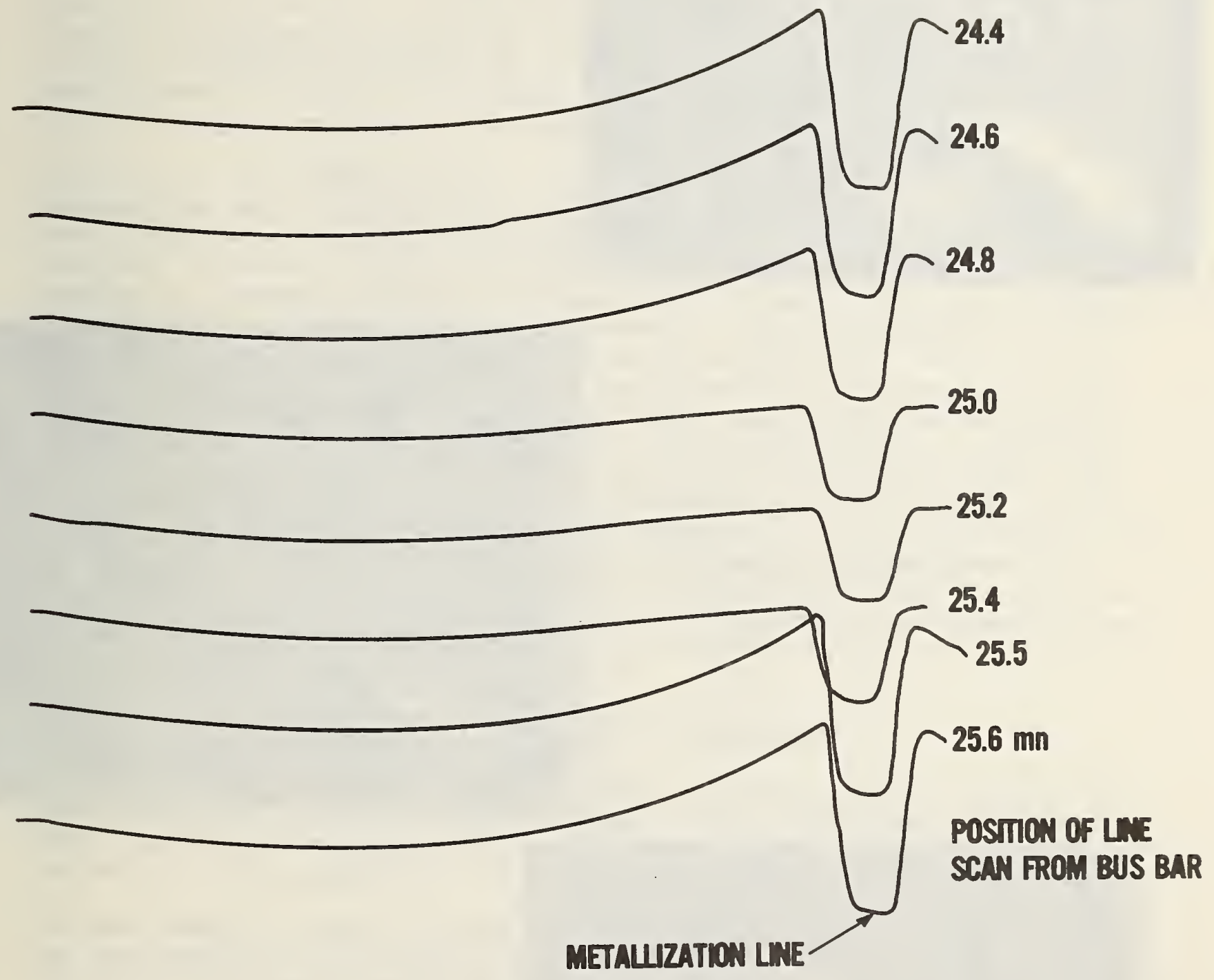

Figure 25. Photoresponse line scans at 200- $\mathrm{m}$ intervals of cell $\mathrm{B}$ in the

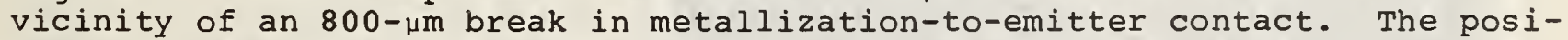
tion of the line scan from the cell bus bar is shown beside each line. The characteristically large slope of the photoresponse line approaching good metallization contact is seen in the top three and bottom two scans. The relatively straight three lines in the center indicate a region of no contact between the emitter and the metallization. 


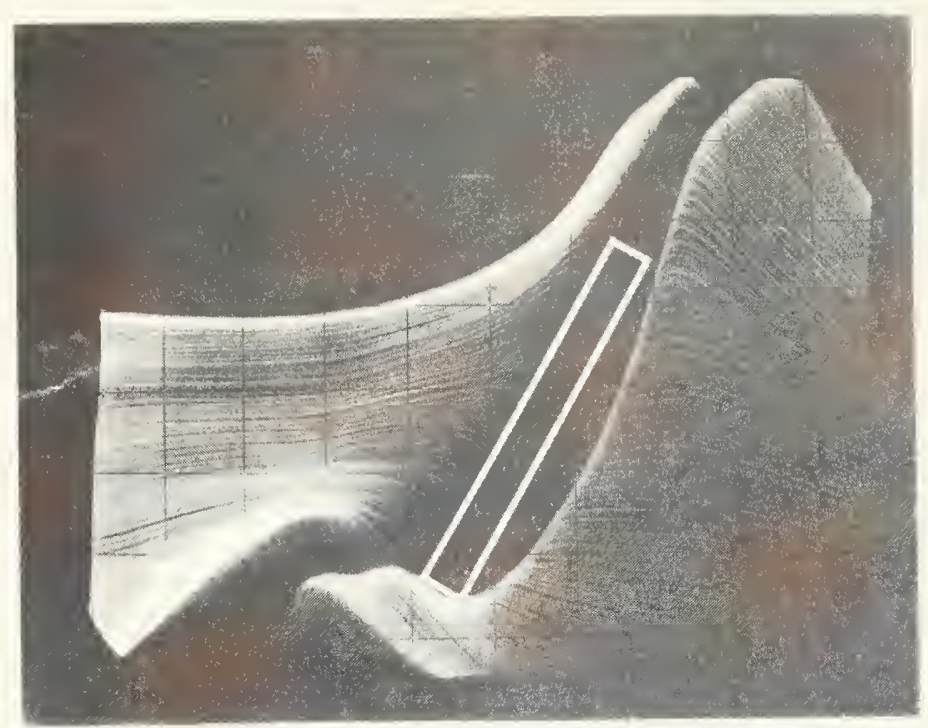

a. 800-um long break.

b. 400- $4 \mathrm{~m}$ long break.
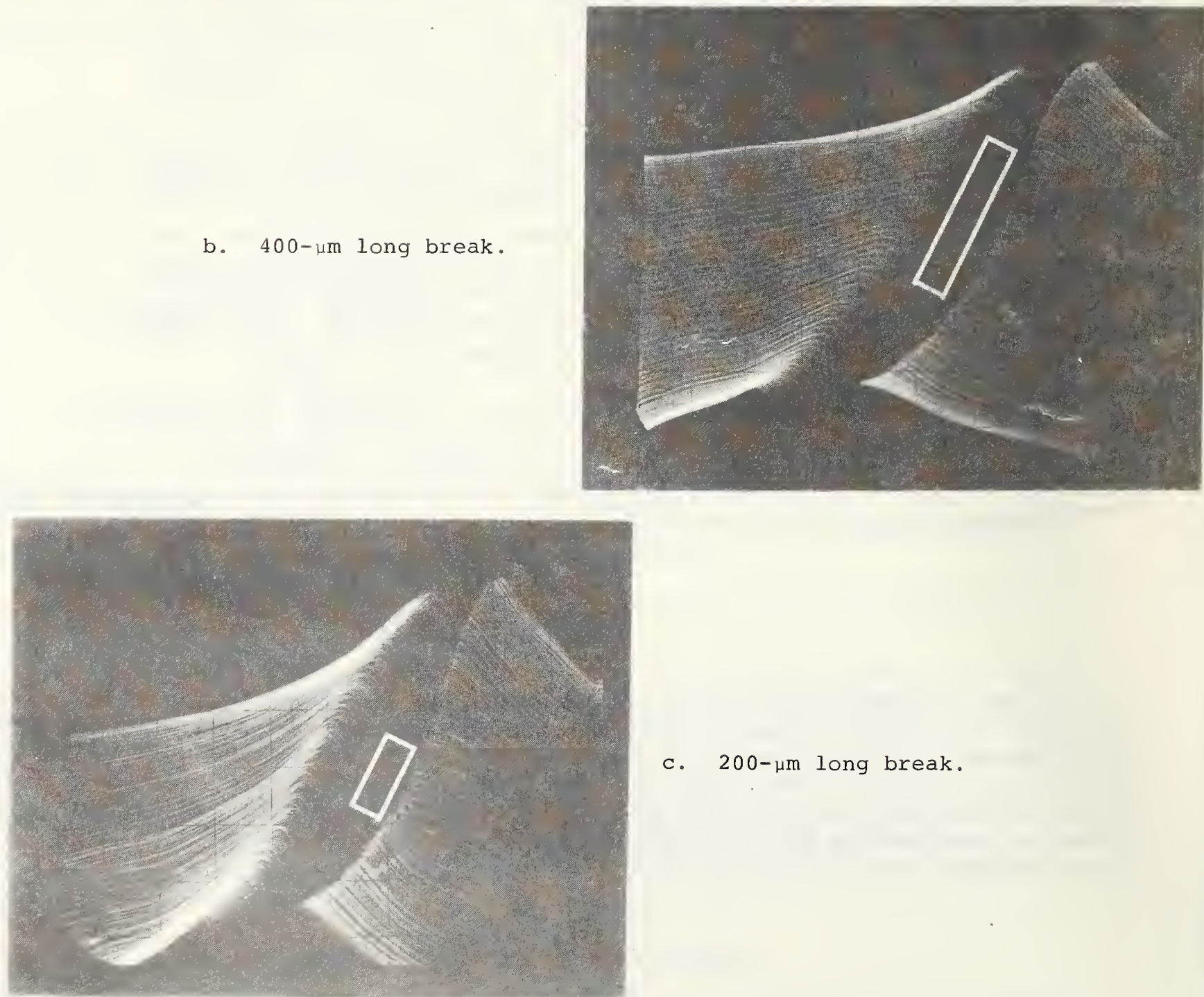

c. 200- $2 \mathrm{~m}$ long break.

Figure 26. Photoresponse raster scan photographs in the vicinity of breaks in the metallization-to-emitter contact. The approximate location of each break is shown by an open rectangle. Note that the display scale was not the same for each photograph. 
test structures. The analysis and assembly procedure involves making all the desired electrical measurements on the reference test structures with a wafer prober system, and then scribing and breaking the pattern into four parts, each containing one of the solar cells. These cells are then bonded with a conductive epoxy to a gold-plated substrate to make the bottom contact. Contact to the top surface is provided by wire bonds from the cell bus bar to an electrically isolated area of the gold-plated substrate. The wire bonds are formed ultrasonically using 25- $\mu$ m diameter aluminum wire. This assembly is then mounted on a small circuit board for ease in handling and making connections to the photoresponse measurement system.

Difficulties have become apparent in this procedure. First, the process of dividing the wafer destroys the inner reference test structures, and second, the delicate wire bonds make subsequent measurements on the remaining reference test structures difficult with an automatic probing device. While wire bonding is a standard technique for integrated circuits, it is not as useful for solar cells. Thick films are often used for the metallization lines and bus bars, allowing more rugged flat electrical connections. Design of a solar cell test pattern for wider use as envisioned in the following sections suggests such a contact system. Standard solar cell metallization printing can be used. Each individual solar cell could be fabricated on a separate wafer or adequate space could be left between cells for scribe lines. Contact to the bus bars of the cells could also be extended to contact pads 10cated outside the ring of reference test structures. This, combined with the flat contacts, would permit measurements to be made on the reference test structure alternately with the photovoltaic measurements. This would be particularly useful if the device were applied to reliability and durability assessment in accelerated stress testing. A possible configuration is shown in figure 27.

\subsection{Step Change in Sheet Resistance}

The intentional defect incorporated in cell $\mathrm{C}$ of the solar cell test pattern demonstrates the potential of this approach to the study of the influence of sheet resistance changes on solar cell photoresponse. An extension of this approach is thus suggested.

The step change in dopant density was seen to be detectable as a change in the photoresponse of the cell as a laser spot is scanned across the cell. However, the process by which the dopant density was changed involved the application of a second diffusion to a specified region of the cell. In addition to increasing the dopant density in the emitter region, other changes were made which have an even greater effect on the photoresponse. As discussed in section 5 , the heating of the entire wafer during the second diffusion step causes the dopant in the masked region to diffuse deeper while the area adjacent to the metallization is exposed to the dopant. The result of this is that the junction depths of the two regions are sufficiently different to substantially enhance the photoresponse of the singly diffused region resulting in the step increase seen in figure 20. As this change in junction depth was not taken into account in the calculated photoresponse equations, it does not show up in figure 5. It would be desirable to study the effects of junction depth and sheet resistance changes independently by producing dopant density variations by ion implantation. As the dopant profiles can be 


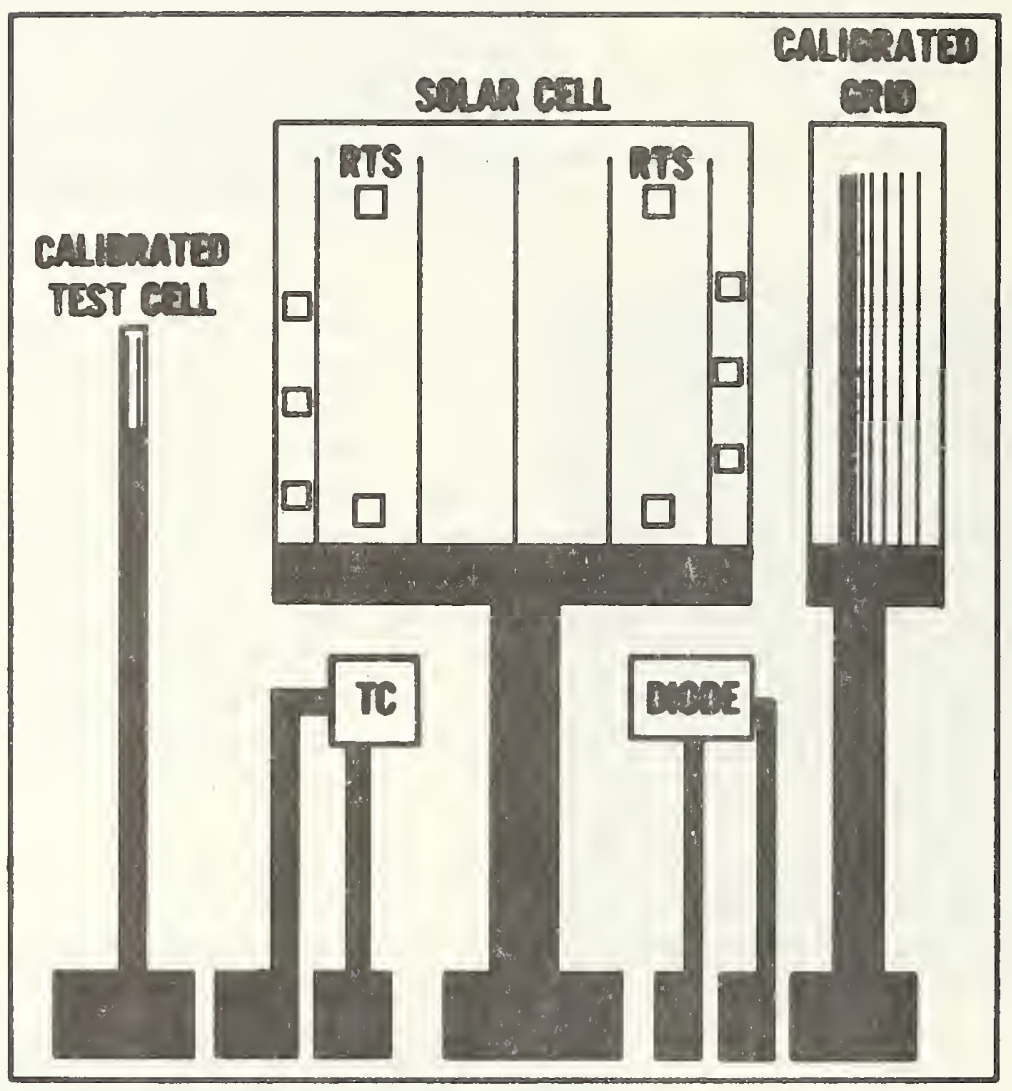

Figure 27. Revised arrangement for the solar cell test pattern showing the location of the diode, the thermocouple, TC, and the reference test structure, RTS. 
accurately controlled for silicon, less ambiguous measurements should be possible.

\subsection{Illumination Uniformity and Intensity Calibration}

Any careful measurement of the photoresponse over the area of a solar cell due to a laser spot while the cell is under general illumination requires either a high degree of uniformity in that illumination or that the degree of nonuniformity be well known. Otherwise, it is the effect of the nonuniformity in illumination that is being measured rather than variation in the photoresponse of the cell itself. The uniformity of the general illumination could most conveniently be measured by fabricating on the solar cell test structure a small cell with independent leads. The output of this cell as it is moved through the illuminated area could then be used to facilitate adjustments in the light source and finally to measure the uniformity of the illumination during an actual scan across the solar cell on the test structure.

In addition to uniformity, the measurement of absolute magnitude of the illumination is important both for intralaboratory reproducibility and for comparison to results between laboratories. Since the regions of interest in this work are considerably smaller than that of the presently available calibration cells, a small reference cell on part of the solar cell test structure is needed. The same cell used for uniformity determination could be used for this purpose if properly calibrated.

\subsection{Temperature Sensor}

The importance of knowing the solar cell surface temperature in making quantitative measurements derives from the $\mathrm{kT} / \mathrm{q}$ factor appearing in the basic equations for cell response. An accurate determination of the cell temperature under scanning conditions is essential when high illumination levels are employed. Independent verification would also be helpful when temperaturecontrolled vacuum chucks are used.

A simple and convenient way to provide a temperature sensor in the solar cell test pattern is to include a thermocouple junction vacuum deposited onto the surface of the silicon wafer adjacent to the solar cells in the pattern. This would ensure good thermal contact with the wafer and, with separate permanent leads attached, temperature measurements could be made during lightbiased scanning. The thermocouple junction should be as small as possible to lessen the effects of light reflection, and the leads should be small to reduce heat conduction. A technique which virtually eliminates the latter problem has been developed by stamper [11] using a three-lead thermocouple.

Alternatively, a separate silicon diode can be fabricated as part of the solar cell test pattern, located adjacent to the solar cell. The diode would be covered during the metallization step to eliminate photoresponse. The forward voltage across the junction due to applied current density $j_{L}$ [eq (7)] would be calibrated against temperature for each diode. These characteristics have been studied for $p-n$ junctions by Sclar and Pollock for the range from 4 to $300 \mathrm{~K}[12]$. 


\subsection{System Resolution}

One of the parameters of a laser scanner that is important to measure and to optimize is the effective laser spot size, or resolution of the system. A rough measure of this quantity may be obtained from the sharpness of the photoresponse cut-off as the laser spot reaches a metallization line. Standard optical methods of measuring resolution, however, employ a calibrated grid of transparant and opaque regions to measure the modulation in the transmitted intensity of a light spot as it is moved across the grid. This same measurement could be made much more conveniently with a set of closely spaced metallization lines deposited on a photosensitive surface as part of the solar cell test pattern. The spacing should vary from a fraction of a micrometer to several hundred micrometers to cover the range of scanners in use. This would aid in the function of the solar cell test pattern as a device to evaluate laser scanners that are being widely used in photovoltaic research and development laboratories.

\section{New Directions}

The investigation of the usefulness of the laser scanner in conjunction with electrical measurements from reference test structures as described in this report has led to the identification of a number of areas for future study. The most immediate is the application of the Sawyer/Lehovec equation for laser-induced photoresponse to the measurement of solar cell sheet resistance as suggested by Sawyer [2] and described in section 8.1 .

\subsection{Contactless Measurement of Solar Cell Sheet Resistance}

The accuracy of the match in the theoretical photoresponse curve between metallization lines and the corresponding line scans obtained on solar cell A of NBS-22 suggests that a measurement of emitter sheet resistance can be made by reversing the process. Using only the normal solar cell output contacts, the procedure consists of first determining the attenuation length $\mathrm{x}_{0}$ by fitting eq (4) to the experimental photoresponse curve. Alternatively, $x_{0}$ can easily be obtained from a simple measurement of $v_{\min } / v_{\max }$ as defined in section 4 .

Equation (10) can be solved for the sheet resistance in terms of known quantities:

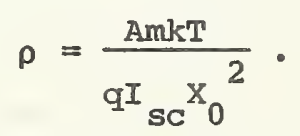

The sheet resistance values calculated for cell A on wafers 1 and 2 using the $x_{0}$ values determined from measurements of $v_{\min }$ and $v_{\max }$ at various levels of light bias are shown in table 4. The agreement of these sheet resistance values with the means of the values determined from direct measurements on reference test structures surrounding the two cell A's improves with the light bias level used. The results in table 4 indicate that it is possible to measure the sheet resistance of this type of solar cells with an accuracy of better than 6 percent using this method, provided that the solar cells are uniform. Only in this case can these sheet resistance determinations be compared to the point measurements of van der Pauw cross resistors. 
Table 4. Comparison of Sheet Resistances Measured by Optical and Electrical Methods.

\begin{tabular}{|c|c|c|c|}
\hline \multirow[t]{2}{*}{$\begin{array}{l}\text { Light. } \\
\text { bias } \\
\text { [suns] }\end{array}$} & \multirow{2}{*}{$\begin{array}{c}\text { Electrical } \\
\text { (van der Pauw) } \\
\rho(e)[\Omega / 0]\end{array}$} & $\begin{array}{c}\text { Optical } \\
\text { (Laser Scanner) } \\
\rho(0)[\Omega / \square]\end{array}$ & $\begin{array}{c}\text { 8 difference } \\
\rho(e)-\rho(0)\end{array}$ \\
\hline & & from $\frac{\min }{V_{\max }}$ & $\rho(e)$ \\
\hline
\end{tabular}

Cell A, wafer 1

\begin{tabular}{|c|c|c|c|c|}
\hline 0.97 & & $51.38 \pm 0.07$ & 45.4 & 11.6 \\
\hline 1.6 & ' & $51.38 \pm 0.07$ & $48 \cdot 3$ & 6.0 \\
\hline
\end{tabular}

Cell A, Wafer 2

\begin{tabular}{llcc}
\hline .63 & $48.1 \pm 1.6$ & 43.21 & 11.3 \\
0.87 & $48.1 \pm 1.6$ & 44.8 & 6.9 \\
1.07 & $48.1 \pm 1.6$ & 47.41 & 1.5 \\
1.38 & $48.1 \pm 1.6$ & 49.70 & -3.3 \\
1.69 & $48.1 \pm 1.6$ & 47.80 & 0.6 \\
2.02 & $48.1 \pm 1.6$ & 49.61 & -3.1 \\
\hline
\end{tabular}


The measurements made during this reporting period were restricted to only two nearly identical cells for a number of different illumination levels. It would be expected that the accuracy of the method would increase with illumination level since the resulting greater curvature in the photoresponse laser scan would permit greater accuracy in the determination of $x_{0}$. This accuracy is particularly important since $x_{0}$ appears as a squared term in eq (12). The next test of the method should be to apply it to a set of solar cells with a range of different sheet resistances determined by independent electrical measurements. If the method proves to be accurate over a significant range of sheet resistances, it should be applied to commercial devices to test its practicality. At that point the preparation of a test method draft may be warranted.

\subsection{On-Iine Computer Use}

A basic conflict exists in the scanning of solar cells or any device whose area is much larger than the detail to be investigated. On one hand it is desirable to scan quickly a cell area of the order of $1 \mathrm{~cm}^{2}$ to determine the location of defects for further study. However, the cracks and point defects that the laser scanner is capable of detecting are on the order of $1 \mu \mathrm{m}$. The problem is one of the resolution of the display of the photoresponse over the area of the cell. Magnification of a flaw the size of $1 \mu \mathrm{m}$ to $1 \mathrm{~mm}$ in the display image would require a display sensor width of $10 \mathrm{~m}$ for each centimeter of cell scanned. Such a display is clearly impractical.

The appropriate solution seems to be that of an on-line minicomputer to store the data from the many lines scans in digital form for display. A software scaling routine would allow the operator to "zoom in" on regions of interest as they are identified on each cell.

To take full advantage of such a system for quantitative measurements, it is essential to be able to control the position of the test cell under the laser spot as discussed in section 3. The precision available in positioning should approximate the resolution limits of the scanner. Such $x-y$ stages with stepping motors which can be computer driven are readily available. The addition of this capability to the laser scanner would expand its range of application and its convenience of use substantially.

\section{Summary}

The photoresponse of solar cells to laser illumination predicted by the calculations of Sawyer [3] and of Iehovec and Fedotowsky [5] were compared to measurements made with the NBS laser scanner on single-crystal test solar cells. The results have provided experimental verification of the calculations and provide the basis for more quantitative applications of the scanner to the diagnostic study of solar cells. Intentionally introduced nonuniformities in sheet resistance, junction depth, and metallization contact were examined with the laser scanner, and the capability of the scanner to detect these nonuniformities was evaluated. The laser photoresponse was found to be very sensitive to changes in junction depth but relatively insensitive to abrupt changes in sheet resistance due to the averaging effect of charge collection to metallization line on both sides of the sheet resistance change. Breaks in top metallization contact to the cell was found to be detectable if 
the length of the break was greater than approximately one-half of the current attenuation length in the cell which is dependent on the level of overall illumination on the cell.

The experience in using the solar cell test pattern NBS-22 designed for this study led to several suggested improvements and additions to the pattern that can facilitate its use in determining the capability of laser scanners in general to make solar cell examinations. Finally, the use of the laser scanner in making measurements of uniform solar cell sheet resistance was investigated and determined to be a very promising method of making the measurement without making contact to the cell except through the normal solar cell electrodes. For measurements not too close to the cell boundaries, the agreement between the sheet resistance determined by scanning the solar cell and that determined by making electrical measurements of van der Pauw sheet resistance on test structures adjacent to the cell were found to agree within an accuracy of 6 percent. Further work on the method is indicated using cells with a wide range of sheet resistances.

\section{ACKNOWLEDGMENTS}

The authors would like to thank Dr. David Sawyer and Dr. Murray Bullis for their careful reading of the text and their helpful suggestions. We also appreciate the helpful discussions with Drs. Sawyer and Lehovec during the course of the experimental work. 


\section{References}

1. Sawyer, D. E., and Berning, D. W., Semiconductor Measurement Technology: A Laser Scanner for Semiconductor Devices, NBS Spec. Publ. 400-24 (February 1977).

2. Sawyer, D. E., Kessler, H. K., and Schafft, H. A., Measurement Techniques for Solar Cells, Annual Report, September 15, 1977 to December 14. 1978, NBSIR 80-2027 (July 1980).

3. Sawyer, D. E., and Kessler, H. K., Laser Scanning of Solar Cells for Display of Cell operating Characteristics and Detection of Cell Defects, IEEE Trans. Electron Devices 27, 864-872 (1980).

4. Sawyer, D. E., Kessler, H. K., Russell, T. J., Lankford, W. F., and Schafft, H. A., Measurement Techniques for Solar Cells, Annual Report, December 15, 1978 to December 14, 1979, NBSIR 80-2181 (January 1981).

5. Lehovec, K., and Fedotowsky, A., Scanning Light Spot Analysis of Faulty Solar Cells, Solid State Electronics 23, 565-576 (1980).

6. Wagner, D. K., Fletcher, R. M., and Ballantyne, J. M., High-Resolution Optical Methods for Characterization of Polycrystalline GaAs Thin Films, IEEE Trans. Electron Devices 27, 2213-2216 (1980).

7. Distefano, T. H., Photodepopulation Technique for the Study of Electronic Traps in Insulators, Semiconductor Measurement Technology: ARPA/NBS Workshop IV. Surface Analysis for Silicon Devices, A. G. Lieberman, Ed., NBS Spec. Publ. 400-23 (March 1976) pp. 189-209.

8. Daniel, C., and wood, F. S., Fitting Fquations to Data; Computer Analysis of Multifactor Data for Scientists and Engineers (wiley Interscience, New York, 1971).

9. Lehovec, K., and Fedotowsky, A., Solar Cell Mathematical Analysis and Computer Simulation, NBS-GCR-80-285 (February 1981).

10. Hovel, H. J., Solar Cells, Semiconductors and Semimetals, Vol. 11, R. K. Willardson and A. C. Beers, Eds., p. 41 (Academic Press, New York, 1975).

11. Stamper, J. A., Differential sensing Controlled Thermocouple, The Review of Scientific Instruments 34, 444-445 (1963).

12. Sclar, N., and Pollock, D. B., On Diode Thermometers, Solid-State EZectronics $15,473-480$ (1972). 
MBS-IIAA (REV. Q-78)

\begin{tabular}{|c|c|c|}
\hline $\begin{array}{l}\text { U.S. DEPT. OF COMM. } \\
\text { BIBLIOGRAPHIC DATA } \\
\text { SHEET }\end{array}$ & $\begin{array}{l}\text { 1. PUBLICATION OR REPORT NO. } \\
\qquad \begin{array}{l|l}\text { NBS GoV'L ACceossion No } \\
\text { NBS } 81-2260\end{array}\end{array}$ & 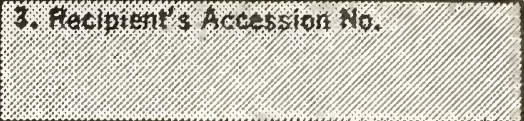 \\
\hline \multirow{2}{*}{\multicolumn{2}{|c|}{$\begin{array}{l}\text { Laser Scanning Measurements on Solar Cell Test Pattern } \\
\text { NBS- } 22\end{array}$}} & $\begin{array}{l}\text { 5. Publication Date } \\
\text { May } 1981\end{array}$ \\
\hline & & 6. Performing Organization Code \\
\hline \multicolumn{2}{|c|}{$\begin{array}{l}\text { 7. AUTHOR(S) } \\
\text { W. F. Lankford, P. Kowalski, and H. A. Schafft }\end{array}$} & 8. Performing Organ. Report No. \\
\hline \multicolumn{2}{|c|}{ 9. PERFORMING ORGANIZATION NAME AND ADDRESS } & 10. Prolect/Task/Work Únit No. \\
\hline \multicolumn{2}{|c|}{$\begin{array}{l}\text { NATIONAL BUREAU OF STANDARDS } \\
\text { DEPARTMENT OF COMMERCE } \\
\text { WASHINGTON, DC } 20234\end{array}$} & $\begin{array}{l}\text { 11. Contract/Grant No. } \\
\text { EG-77-C-01-4042 } \\
\text { Subcontract DX-1-1076-1 }\end{array}$ \\
\hline \multirow{2}{*}{\multicolumn{2}{|c|}{$\begin{array}{l}\text { 12. SPONSORING ORGANIZATION NAME AND COMPLETE ADDRESS (Streot, City, State, ZIP) } \\
\text { Solar Energy Research Institute } \\
1536 \text { Cole Boulevard } \\
\text { Golden, Co } 80401\end{array}$}} & $\begin{array}{l}\text { 13. Type of Report \& Period Covered } \\
\text { Final } \\
6 / 1 / 80 \text { to } 11 / 30 / 81\end{array}$ \\
\hline & & 10. Sponsoring Agency Code \\
\hline \multicolumn{3}{|l|}{ 15. SUPPLEMENTARY NOTES } \\
\hline
\end{tabular}

16. ABSTRACT (A 200-word or less factual summary of most significant information. If document includes a significant bibliography or literature survey, mention it here.)

The NBS laser scanner has been used to make measurements on the solar cell test pattern, NBS-22, to verify the theoretical calculations of Sawyer, Lehovec, and Fedotowski. The photovoltaic response from cells with controlled sheet resistance step changes and breaks in the metallization contact to the cell was measured and compared to the theoretical predictions. Laser scanner limits of resolution were identified and proposed improvements were discussed. Preliminary measurements indicate that it is possible to measure the sheet resistance of the emitter layer of solar cells with an accuracy of several percent, using the laser scanner.

17. KEY WORDS (six to twelve entries; alphabetical order; capitalize only the first letter of the first key word unless a proper name; separated by semicolons) Laser scanner; model calculations; photovoltaic cells; sheet resistance; solar cells; solar cell defects; test structures

18. AVAILABILITY

For Official Distribution. Do Not Release to NTIS

Order From Sup. of Doc., U.S. Government Printing Office, Washington, DC 20402, SD Stock No. SNO03-003-

$x$ Order From National Technical Information Service (NTIS), Springfield, VA. 22161 x. Unlimited

\begin{tabular}{|l|c|}
\hline $\begin{array}{l}\text { 19. SECURITY CLASS } \\
\text { (THIS REPORT) }\end{array}$ & $\begin{array}{c}\text { 21. NO. OF } \\
\text { PRINTED PAGES } \\
\text { UNCLASSIFIED }\end{array}$ \\
\hline $\begin{array}{l}\text { 20. SECURITY CLASS } \\
\text { (THIS PAGE) }\end{array}$ & 53 \\
UNCLASSIFIED & $\$ 8.00$ \\
\hline
\end{tabular}





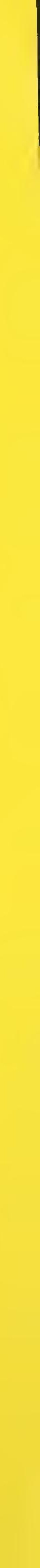


